\title{
Stroke: Working toward a Prioritized World Agenda
}

\author{
Vladimir Hachinski ${ }^{1}$, Geoffrey A. Donnan ${ }^{5, a, h}$, Philip B. Gorelick ${ }^{8, b, h}$, Werner Hacke $^{30, c, h}$, \\ Steven C. Cramer ${ }^{10, d, h}$, Markku Kaste ${ }^{33, e, h}$, Marc Fisher ${ }^{14, f, h}$, Michael Brainin ${ }^{36, g, h}$, Alastair \\ M. Buchan ${ }^{37, a}$, Eng H. Lo ${ }^{15, a}$, Brett E. Skolnick ${ }^{17, a}$, Karen L. Furie ${ }^{15, b}$, Graeme J. Hankey ${ }^{7, b}$, \\ Miia Kivipelto ${ }^{41, b}$, John Morris ${ }^{18, b}$, Peter M. Rothwell ${ }^{38, b}$, Ralph L. Sacco ${ }^{19, b}$, Sidney C. \\ Smith Jr.21,43,b, Yulun Wang ${ }^{12, b}$, Alan Bryer ${ }^{44, c}$, Gary A. Ford ${ }^{39, c}$, Costantino ladecola ${ }^{25, c}$, \\ Sheila C.O. Martins ${ }^{45, c}$, Jeff Saver ${ }^{13, c}$, Veronika Skvortsova ${ }^{46, c}$, Mark Bayley ${ }^{3, d}$, Martin M. \\ Bednar $^{26, d}$, Pamela Duncan ${ }^{22, d}$, Lori Enney ${ }^{23, d}$, Seth Finklestein ${ }^{16, d}$, Theresa A. Jones ${ }^{27, d}$, \\ Lalit Kalra ${ }^{40, d}$, Jeff Kleim ${ }^{20, d}$, Ralph Nitkin ${ }^{28, d}$, Robert Teasell ${ }^{2, d}$, Cornelius Weiller ${ }^{31, d}$, \\ Bhupat Desai ${ }^{11, e}$, Mark P. Goldberg ${ }^{18, e}$, Wolf-Dieter Heiss ${ }^{32, e}$, Osmo Saarelma ${ }^{34, e}$, Lee H. \\ Schwamm ${ }^{15, e}$, Yukito Shinohara ${ }^{47, e}$, Bhargava Trivedi $^{9, \mathrm{e}}$, Nils Wahlgren ${ }^{41, \mathrm{e}}$, Lawrence K.
}

(C) 2010 American Heart Association. Inc.

Vladimir Hachinski, MD, FRCPC, DSc, University of Western Ontario, University Hospital, 339 Windermere Road, London, Ont. N6A 5A5 (Canada), Vladimir.Hachinski@lhsc.on.ca

Working Groups:

a Basic Science, Drug Development, and Technology

${ }^{b}$ Stroke Prevention: Broadening the Approach and Intensifying the Efforts

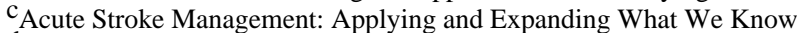

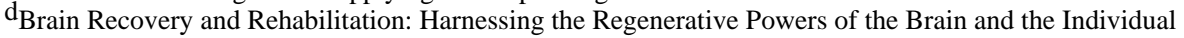

Into the 21st Century: The Web, Technology, and Communications: New Tools for Progress

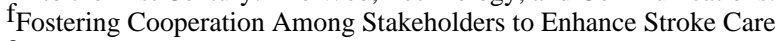

gEducating and Energizing Professionals, Patients, the Public, and Policymakers

$\mathrm{h}_{\text {The coordinator of each group. }}$

The work of the coordinators is deemed to have been equal.

The other authors are listed according to the sequence of their groups and alphabetically, and their work is also deemed to be equal to each other's.

Disclosures

G.A.D. ${ }^{\text {a }}$ received other research support from Boehringer Ingelheim (BI) and Sanofi-Aventis; Consultant/Advisory Board for BI, Servier, Sanofi-Aventis, Bristol Myer Squibb. P.B.G. received Speakers Honoraria from BI; Consultant/Advisory Board for Bayer, Abott, Takeda.S.C.C. ${ }^{\text {d, }}$ h received research grant from GlaxoSmith-Kline (GSK) and Stem Cell Therapeutics; Consultant/Advisory Board for GSK, Stem Cell Therapeutics, Johnson and Johnson, Photothera (all significant) and Pfizer Inc, Allergan Inc, Grupo Ferrer SA (all modest). M.K. ${ }^{\text {eh }}$ received Honoraria from BI, PAION AG, Servier, Forest Research Laboratories Inc, Neurobiological Technologies Inc, and Lund beck AS for participating in the Steering Committee meetings of ProFESS, PERFORM, ANCROD, and all ECASS, DIAS and CEPO trials, and for giving lectures in national and international meetings sponsored by the above mentioned companies and Sanofi-Aventis and BMS; Consultant/Advisory Board for BI, PAION AG,Servier, Forest Research Laboratories Inc, Neurobiological Technologies Inc, and Lund beck AS.B.E.S. ${ }^{\mathrm{a}}$ is an employee of Novo Nordisk. K.L.F. ${ }^{\mathrm{b}}$ received IRIS trial funding through National Institute of Neurological Disorders and Stroke (NINDS). G.J.H. b received Speakers Honoraria from Pfizer, SanofiAventis; Consultant/Advisory Board for BI, Sanofi-Aventis. J.C.M. ${ }^{b}$ participated/is currently participating in clinical trials of antidementia drugs sponsored by Elan, Eli Lilly and Company, Wyeth; Consultant/ Speaking Honoraria from AstraZeneca, BristolMyers Squibb, Genentech, Lilly, Merck, Novartis, Pfizer, Schering Plough, Wyeth Elan. R.L.S. ${ }^{b}$ received a research grant from NINDS (Northern Manhattan Stroke Study). Y.W. ${ }^{b}$ is CEO and serves as/on Consultant/Advisory Board of InTouch Health, Goleta, Calif. G.A.F. c: payment to institution from companies undertaking stroke research including Lund beck, Mitsubishi, PAION, BI for trial related activities; payment to institution for administrative support of UK SITS database, BI; personal payment for educational lectures (modest) and advisory board (modest), BI, Lund beck. S.C.O.M. ${ }^{\mathrm{c}}$ received lecture fees from BI.J.S. ${ }^{\mathrm{C}}$ is employed at University of California; received research grants from National Institutes of Health (NIH); Consultant/Advisory Board of Talacris, Syquil, EV3, AGA, Brainsbok; University of California receives research grants from NIH and hundreds of industry companies; University of California has patent interest in the Merci retriever. M.M.B. ${ }^{d}$ is an employee of Pfizer Inc. P. D. ${ }^{d}$ is an employee of Duke University. L.E. ${ }^{\mathrm{d}}$ is an employee of GSK.S.F. ${ }^{\mathrm{d}}$ is an employee of Biotrofix, Inc and Massachusetts General Hospital (significant); has ownership interest in Biotrofix, Inc; and Consultant/Advisory Board for Pfizer, GSK, Johnson and Johnson, Acorda,

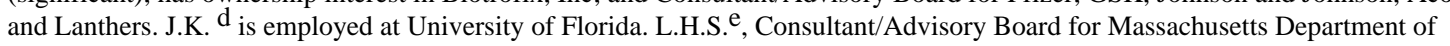
Public Health and Phreesia Inc. B.T. ${ }^{\text {e }}$ is employed at Southern IL Healthcare. N.W. ${ }^{\text {e }}$ is employed at Karolinska Institute. L.K.W. ${ }^{\text {e }}$ is employed at Chinese University of Hong Kong. S.P. ${ }^{f}$ is employed at the American Heart Association. V.H.,W.H. c,h ,M.F. f,h,

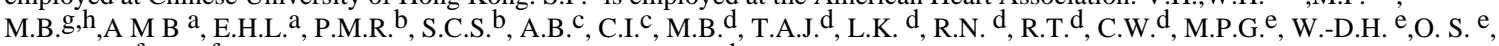
Y.S. ${ }^{\mathrm{e}}$, A.H. ${ }^{\mathrm{f}}$, B.N. ${ }^{\mathrm{f}}$, N.M.B.g,S.M.D.g,L.B.G.g,D.L.g,J.T.g,M.K. ${ }^{\text {, }},{ }_{\text {,V.S. }}{ }^{\mathrm{c}}$, and B.D. ${ }^{\mathrm{e}}$ have no conflicts to report. 


\author{
Wong $^{48, e}$, Antoine Hakim ${ }^{4, f}$, Bo Norrving ${ }^{42, f}$, Stephen Prudhomme ${ }^{29, f}$, Natan M. \\ Bornstein $^{49,9}$, Stephen M. Davis ${ }^{6,9}$, Larry B. Goldstein ${ }^{24,9}$, Didier Leys ${ }^{50,9}$, and Jaakko \\ Tuomilehto $35, \mathrm{~g}$
}

${ }^{1}$ Department of Clinical Neurological Sciences, London Health Sciences Center, University of Western Ontario ${ }^{2}$ St. Joseph's Healthcare London, London, Ont. ${ }^{3}$ Toronto Rehabilitation Institute, Toronto, Ont. ${ }^{4}$ The Canadian Stroke Network, The University of Ottawa and the Ottawa Hospital Research Institute, Ottawa, Ont., Canada ${ }^{5}$ Florey Neurosciences Institutes, Carlton South Victoria ${ }^{6}$ Director of Neurology, Royal Melbourne Hospital and University of Melbourne, Melbourne, Vic.

${ }^{7}$ Royal Perth Hospital, Perth, W.A., Australia ${ }^{8}$ University of Illinois at Chicago, Chicago, III. ${ }^{9}$ Southern Illinois Healthcare, Carbondale, III. ${ }^{10}$ University of California - Irvine, Orange, Calif. ${ }^{11}$ Pomona Valley Hospital Medical Center, Pomona, Calif. ${ }^{12}$ InTouch Health, Goleta, Calif. ${ }^{13}$ University of California at Los Angeles Stroke Center, Los Angeles, Calif. ${ }^{14}$ University of Massachusetts Medical School, Worcester, Mass. ${ }^{15}$ Massachusetts General Hospital, Charlestown, Mass. ${ }^{16}$ Biotrofix, Inc., Waltham, Mass. ${ }^{17}$ Novo Nordisk, Princeton, N.J.

${ }^{18}$ Washington University School of Medicine, St. Louis, Mo. ${ }^{19}$ President-elect, AHA, University of Miami, Miami, Fla. ${ }^{20}$ University of Florida, Gainesville, Fla. ${ }^{21}$ Center for Cardiovascular Science and Medicine, University of North Carolina, Chapel Hill, N.C. ${ }^{22}$ Duke University, Durham, N.C. ${ }^{23}$ GlaxoSmithKline, Durham, N.C. ${ }^{24}$ Duke University and Durham VA Medical Center, Durham, N.C. ${ }^{25}$ Weill Cornell Medical College, New York, N.Y. ${ }^{26}$ Neuroscience Research Unit, Pfizer Inc., Groton, Conn. ${ }^{27}$ University of Texas at Austin, Austin, Tex. ${ }^{28}$ National Center for Medical Rehabilitation, National Institute of Child Health and Human Development, National Institutes of Health, Rockville, Md. ${ }^{29}$ American Heart Association, Dallas, Tex., USA ${ }^{30}$ University of Heidelberg, Heidelberg ${ }^{31}$ University of Freiburg, Freiburg ${ }^{32}$ Max Planck Institute for Neurological Research, Köln, Germany ${ }^{33}$ Helsinki University Central Hospital, University of Helsinki ${ }^{34}$ Terveystalo Medical Center ${ }^{35}$ University of Helsinki, Helsinki, Finland ${ }^{36}$ University DonauUniversität Krems, Krems, Austria ${ }^{37}$ University of Oxford ${ }^{38} \mathrm{John}$ Radcliffe Hospital, Oxford ${ }^{39}$ Newcastle University, Newcastle upon Tyne ${ }^{40}$ Kings College London, London, UK ${ }^{41}$ Karolinska Institute, Stockholm ${ }^{42}$ Lund University Hospital, Lund, Sweden ${ }^{43}$ President-elect, World Heart Federation, Geneva, Switzerland ${ }^{44}$ Groote Schuur Hospital and University of Cape Town, Cape Town, South Africa ${ }^{45} \mathrm{Hospital}$ De Clinicas, Porto Alegre, Brazil ${ }^{46}$ Russian State Research Stroke Institute, Moscow, Russian Federation ${ }^{47}$ Tachikawa Hospital, Tokyo, Japan ${ }^{48}$ Chinese University of Hong Kong, Sha Tin, Hong Kong, China ${ }^{49}$ Tel Aviv Sourasky Medical Center, Tel Aviv University, Tel Aviv, Israel ${ }^{50}$ University Lille Nord de France, Lille, France

\title{
Abstract
}

Background and Purpose-The aim of the Synergium was to devise and prioritize new ways of accelerating progress in reducing the risks, effects, and consequences of stroke.

\begin{abstract}
Methods-Preliminary work was performed by 7 working groups of stroke leaders followed by a synergium (a forum for working synergistically together) with approximately 100 additional participants. The resulting draft document had further input from contributors outside the synergium.

Results-Recommendations of the Synergium are: Basic Science, Drug Development and Technology: There is a need to develop: (1) New systems of working together to break down the prevalent 'silo' mentality; (2) New models of vertically integrated basic, clinical, and epidemiological disciplines; and (3) Efficient methods of identifying other relevant areas of science. Stroke Prevention: (1) Establish a global chronic disease prevention initiative with stroke as a major focus. (2) Recognize not only abrupt clinical stroke, but subtle subclinical stroke, the commonest type of cerebrovascular disease, leading to impairments of executive function. (3) Develop, implement and evaluate a population approach for stroke prevention. (4) Develop public
\end{abstract}


health communication strategies using traditional and novel (e.g., social media/marketing) techniques. Acute Stroke Management: Continue the establishment of stroke centers, stroke units, regional systems of emergency stroke care and telestroke networks. Brain Recovery and Rehabilitation: (1) Translate best neuroscience, including animal and human studies, into poststroke recovery research and clinical care. (2) Standardize poststroke rehabilitation based on best evidence. (3) Develop consensus on, then implementation of, standardized clinical and surrogate assessments. (4) Carry out rigorous clinical research to advance stroke recovery. Into the 21st Century: Web, Technology and Communications: (1) Work toward global unrestricted access to stroke-related information. (2) Build centralized electronic archives and registries. Foster Cooperation Among Stakeholders (large stroke organizations, nongovernmental organizations, governments, patient organizations and industry) to enhance stroke care. Educate and energize professionals, patients, the public and policy makers by using a 'Brain Health' concept that enables promotion of preventive measures.

Conclusions-To accelerate progress in stroke, we must reach beyond the current status scientifically, conceptually, and pragmatically. Advances can be made not only by doing, but ceasing to do. Significant savings in time, money, and effort could result from discontinuing practices driven by unsubstantiated opinion, unproven approaches, and financial gain. Systematic integration of knowledge into programs coupled with careful evaluation can speed the pace of progress

\section{Keywords}

Prevention; Rehabilitation; Stroke; Translational; Treatment

Birthdays invite reflection and planning. The journal Stroke has turned 40, providing not only an occasion to celebrate the past, but also an opportunity to help shape the future. Most of the leaders in stroke have been involved with the journal as authors, reviewers, or editors, providing an umbrella for collaboration. The participants of this synergium are leaders in the field and although the event was supported by major stroke organizations worldwide, it was a gathering of individuals interested in finding common solutions.

A result has been a Synergium, a word coined by the first author to describe a forum for working synergistically together. Seven working groups each suggested 3 main recommendations for progress that were refined during a 1-day face-to-face meeting. In addition, approximately 100 other participants and contributors from outside the synergium provided input to the final document.

\section{The Past 40 Years}

More progress has been made in stroke over the past 4 decades than in the previous 4 millennia. In 1970, a landmark paper showed that hypertension was a strong risk factor for all types of stroke [1]. Thereafter, other major risk factors for stroke were identified. Subsequent studies showed that many risk factors can be reduced and that their control decreases the incidence of stroke. The late 1970s saw the first proof that aspirin prevents stroke [2]. This was followed by the introduction of other efficacious antiplatelet agents. The first modern comprehensive stroke unit was inaugurated in 1975 [3], and tissue plasminogen activator's effectiveness in acute stroke was demonstrated in 1995 [4]. Carotid endarterectomy was shown to prevent stroke in selected patients and angioplasty and stenting are currently being tested for similar purposes. Coiling offers an alternative to brain aneurysm and arteriovenous malformation surgery. Brain imaging has revolutionalized the diagnosis of stroke and the management of patients with stroke. Steady progress enhances our understanding of the mechanisms of brain injury, repair, plasticity, and recovery. Each of the previous Editors-in-Chief of Stroke (Clark Millikan, Fletcher McDowell, Henry 
Barnett, Oscar Reinmuth, and Mark Dyken) summarized the main developments and issues in the field during their tenures, covering the years 1970 to 2000 [5-9]. The developments in subsequent years have been documented in the annual 'Advances' feature of Stroke.

\section{Paradoxes of Progress}

Progress breeds paradoxes. Stroke is preventable yet is increasing globally. The same few major risk factors account for much of the leading health problems of the world but remain uncontrolled in the majority of affected individuals. Management of risk factors is the most readily applicable and affordable part of our knowledge, but prevention is neglected, and most environments are inhospitable to healthy living.

Although many advances in the understanding of excitotoxicity, neurotransmitter depletion, oxidative stress, mitochondrial failure, inflammation, and apoptosis have occurred, this has been accomplished in relative isolation from the knowledge gained on the same mechanisms that underlie other major afflictions of the brain such as Alzheimer disease, Parkinson disease, epilepsy, multiple sclerosis, and brain trauma.

Although the symptoms of stroke are well described, the majority at risk do not recognize their significance. In 1 study, only 1 in 6 individuals were aware that a treatment for stroke exists and that at the time of the study, it had to be given no more than $3 \mathrm{~h}$ after symptom onset [10]. In stroke, we know that time is brain, but too few brains arrive in time. Although we have learned to treat transient ischemic attack as an emergency, only approximately 1 in 8 of patients with first-time stroke have a prior transient ischemic attack [11]. We must find other ways of identifying those at high risk for stroke. Subclinical ('silent') strokes are the most common type of stroke, executive function impairment being its earliest manifestation, but this fact is barely recognized and cognition seldom measured [12]

Stroke unit care improves outcomes of patients of all ages, stroke types, and severities but remains the exception rather than the rule in stroke care. The understanding of the neurobiology of brain injury, repair, and plasticity has advanced, but no histoprotective or reparative drug has yet proved efficacious.

Stroke rehabilitation works but is largely unavailable for the time and intensity required. Effective drugs are not accessible or affordable in many developing countries nor used optimally in developed ones. Unproven, costly, or misdirected practices continue to drain resources and prevent the pursuit of more cost-effective approaches.

Although the challenges are daunting, the achievements of the past 4 decades are inspiring, having witnessed the transformation of stroke from an area notable for diagnostic precision and therapeutic impotence to a field ripe for further advances in prevention, acute treatment, and rehabilitation.

\section{Groups' Recommendations}

\section{Basic Science, Drug Development, and Technology}

Step 1: Address Unmet Needs-In all aspects of basic science, drug development, and technology, there is clearly a need to 'do things differently' if there is to be a major advance in the development of new interventions [13,14]. Over the last few years, there has been a dearth of advances that have limited genuine leaps in the understanding of the basic science and patho-genesis of stroke, and hence new targets for therapy $[15,16]$. To counter this, a radical approach is suggested in the following areas.

\section{Recommendations}


1. Establish a New Taxonomy of Disease. This could be based on the genetics or another taxonomy that makes scientists and clinical investigators think about the disease process in a completely different way. The natural consequence of this would be the development of personalized medicine [17]. A simple example might be the genetic basis of vascular collateralization.

2. Learn From Other Scientific Disciplines and Diseases. It is time to step into other domains so that knowledge in other areas may be readily applied to the problem of stroke. In other words, we need to scan the scientific landscape to embrace new ideas and approaches.

3. Challenge Existing Models of Disease and Embrace Even More Basic Models to Have a More 'Blue Sky Approach' to Science. Studies in Drosophila, worms, and zebra fish, among others, might generate novel new ideas about the stroke process [18-20]. Yet, at the same time, pursue more clinical models with human cells, tissue, and samples. For example, sampling in patients undergoing carotid endarterectomy or in patients subjected to transient cerebral ischemia during neurosurgical procedures.

\section{Step 2: Implement 3 Approaches That Will Accelerate the Capacity to Address Unmet Needs-There are processes that could be put in place, which may result in needs being met earlier rather than later.}

\section{Recommendations}

1. Develop new systems of collaboration to break down the silo mentality currently rife in the stroke community. This could involve the gathering together of basic and clinical scientists from a variety of disciplines and putting them to work to solve major stroke problems. Alternatively, it could involve adding 1 or 2 'odd ball' players to existing teams to encourage them to think outside the box. For example, drosophila models have been used for Parkinson disease. Hypoxia-inducible factor-1a responses are conserved from flies to mammals. Can we build on these fundamentals for stroke? In horseshoe crabs (living fossils), coagulation and immune systems are merged. Can we leverage this type of evolutionary biology to dissect and target the links between inflammation and thrombosis in stroke? Evolutionary biology also indicates that neurogenesis and angiogenesis share common genes and pathways. Can we use these principles to develop new methods for stroke repair?

2. Be alert to new models of disease that may vertically integrate basic, clinical, and epidemiological disciplines. For example, could advances in the understanding of infectious diseases or inflammation dramatically change our thinking about stroke pathogenesis?

3. Develop efficient methods of scanning other areas of science to enhance the likelihood of generating new ideas/concepts as well as information likely to be of use in developing new targets, new technologies, and better translational processes.

\section{How, When, and by Whom Should These Goals Be Achieved?}

How-In establishing the new systems described earlier, investigators will need to work in different ways. For example, sabbaticals and exchange programs and publication in completely novel areas could improve the cross-fertilization process. Mechanisms should be 
established that will encourage investigators by measuring the impact and novelty of their work rather than the current trend based on a researcher's number of publications and citations. A broad platform of stroke education should provide the underpinnings for this change (see 'Education' section) with a focus on national research institutions and, perhaps, the establishment of similar global institutions to cross country/cultural boundaries.

By Whom-Scientific leaders around the world (organizations, institutes, and others) need to bring together these new and novel teams. Industry (e.g., pharmaceuticals, biotechnology) should also be involved with a clear interface with the academic, regulatory, and government world. Government funding agencies should stimulate this new collaborative paradigm by providing funding for think tanks, which could be local, national and, even more importantly, global.

\section{Stroke Prevention: Broadening the Approach and Intensifying the Efforts}

\section{Introduction}

Major chronic diseases such as stroke, heart disease, cancer, Alzheimer disease and vascular cognitive impairment may be linked by common risk factors and patho-physiological mechanisms. Few simple steps like eating a balanced diet, exercising, maintaining optimal body weight, avoiding smoking, and limiting alcohol consumption can reduce risk of stroke by up to $80 \%[21,22]$. The occurrence of shared risk factors and possible common pathophysiological mechanisms (e.g., inflammation, endothelial dysfunction) [23] provide a backdrop for the establishment of chronic disease prevention or health preservation networks.

We propose 3 steps to influence future stroke prevention. The approach includes novel means to enhance stroke prevention and integrate strategies from within and outside the medical field with an emphasis on synergistic opportunities and collaborations.

\section{Step 1: Establish a Global Chronic Disease Prevention Initiative That Includes Stroke as a Major Focus among a Cluster of Conditions-The Chronic Disease} Action Group has provided a call to action to encourage, support, and monitor activity on the implementation of evidence-based efforts to achieve global, regional, and national programs to prevent and control chronic diseases [24]. This group emphasizes the control of 3 key modifiable lifestyle risks: unhealthy diet, physical inactivity, and tobacco habit. Multisectorial policies as well as long-term, sustainable action plans are encouraged to empower individuals, families, and communities to affect health-conscious behavioral change. The creation of the Global Noncommunicable Disease Network (NCDnet) [25] also focuses to reduce risk, morbidity, and mortality related to 4 risk factors (tobacco use, physical inactivity, unhealthy diets, and the harmful use of alcohol). It is a global collaborative effort between the World Health Organization (WHO), member states, international partners, and other stakeholders for the prevention and control of noncommunicable diseases.

Recommendations

1. Develop a leadership group that will work with existing organizations to set and advocate a chronic disease prevention agenda with stroke as a major focus and the establishment of formal strategies to reduce unhealthy lifestyle and other risk factors.

2. Establish collaborations between and representation of major health organizations and/or advocacy groups (e.g., WHO, World Federation of Neurology [WFN], World Stroke Organization [WSO], World Heart 
Federation, National Institutes of Health $[\mathrm{NIH}]$, and Fogarty International Center, Centers for Disease Control and Prevention [CDC], American Heart Association [AHA], European Stroke Organization [ESO], Chronic Disease Action Group, health maintenance organizations, etc).

3. Incorporate mechanisms for cost-effective research monitoring into the overall strategy.

4. Government and industry should be represented in these collaborations.

\section{Step 2: Use and Promote the Population Approach for Stroke Prevention}

Recommendations

Newer approaches in the United States and some other regions may include:

1. Generate a paradigm shift among medical insurance providers, government, and health professionals toward a major emphasis on adequate and effective preventive health care and education programs.

2. Establish collaborations among the global chronic disease prevention group, local stroke health advocacy organizations, and governmental chronic disease prevention offices.

3. Use community health workers to provide a means to assist in providing access to health care, adherence to treatment regimens, and overall adoption of ideal cardiovascular health at the community level.

4. Develop positive incentives for: (a) physicians who successfully achieve lifestyle risk control in their patients (e.g., pay-for-performance); and (b) patients/workers who adhere to healthy lifestyle behaviors.

5. Incorporate a broader use of global vascular risk screening tools.

6. Secure funding for additional research to determine the benefits of healthy lifestyle behavior and the most effective ways to modify behavior.

7. Study, for future application, other strategies such as legislation for and education of the community about lowering salt in the diet and polypill strategies [26] in conjunction with healthy lifestyle behavior.

\section{Step 3: Develop Public Health Communication Strategies Using Traditional and Novel (Social Media/Marketing) Techniques-The basic components of} establishing a public health communication strategy include [27] (a) identification of the health problem and target audience; (b) determine if the communication should be part of the intervention and, if so, strategies to best reach the audience; (c) development and testing of communication concepts, messages, and materials, including culturally appropriate messages for selected populations; (d) implementation of a health communication program based on the pretest results; and (e) assessment of the effectiveness of the messages and modification of the program accordingly. Traditional public health communication channels have included public service announcements, commercials, and newspapers, each carrying advantages and disadvantages.

Recommendations

1. An evidence-based communication approach is required and partnership with an organization with substantial experience in public health communication (e.g., WHO, WSO, AHA) is desirable. 
2. Consider establishing a centralized web site for chronic disease prevention inclusive of stroke prevention and social media/ marketing, including but not limited to Twitter, Facebook, MySpace, LinkedIn, YouTube, and blogs. Because of the high penetration use rates of the Internet and cell phones, these communication vehicles should be considered for communicating messages and researched for cost-effectiveness.

3. Overall, the concept of development of a central 'power grid' for chronic disease prevention messaging could be accomplished. Local experts should be consulted to help develop and tailor individual, smart communication systems by area.

\section{Acute Stroke Management: Applying and Expanding What We Know}

\section{Introduction}

The establishment of stroke units and stroke centers has been the most significant contribution to the field of acute stroke management. Stroke units are an effective intervention for the vast majority of stroke victims. Stroke centers along with prehospital system organization, access to rehabilitation, and secondary prevention improve the quality of stroke care.

Enormous lobbying to reach policymakers has been pivotal to all advances in the development of stroke care systems to date. Once 'stroke' has reached political awareness, smooth implementation of care systems follows. The activities may be at the state or provincial level or even at the national level of countries such as Russia, Brazil, Spain, or the United Kingdom. The political will to improve stroke care will allow new activities in the field of stroke to be launched. Nation-or statewide documentation, standards, and quality control instruments can be implemented and more financial resources made available for the development of stroke management and prevention initiatives.

The role of physicians in initiating and guiding such developments is paramount. The achievements in the prehospital system in the United States and in the statewide stroke unit programs in Germany, Brazil, Spain, and Russia were only possible with the enormous input of stroke physicians. Large-scale application of the Scandinavian stroke unit model has increased access to throm-bolytic therapy and reduced the case fatality rate leading to remarkable improvement in the quality of stroke care [28]. This should continue to be a major source of strength and direction.

Stroke care is expensive. It has to be supported in a zero-sum game of allocation in the setting of overall shrinking budgets of general health care, an action that will be not be warmly welcomed by colleagues in other fields. A helpful and key, evidence-supported message is that improvements in stroke care frequently brings net health expenditure savings to governments by reducing rehabilitation, nursing home, and lost productivity costs.

Although capitalizing on existing therapies is well justified, flexibility has to be built into the system to facilitate the successful application of new diagnostic and therapeutic approaches. It should be possible to introduce new tools and technologies, revise protocols, and modify the composition of the stroke care team to fit the requirement of new developments in the field. By doing so, the stroke care system will remain flexible and will be amenable to incorporate advances that will continue to improve the care of the patient with stroke. 


\section{Steps for Improving Stroke Care Worldwide}

Step 1: Establishment of Stroke Centers and Stroke Units to Assist Patients with Acute Stroke as a Priority-Stroke center hospitals with organized stroke unit care have made the most significant contribution to current stroke management. Efforts should be made to establish hospitals with stroke unit care in locations accessible to all patients with stroke to reduce the global burden of stroke. These specialized centers should be organized according to the local and regional needs and classified in different levels of complexity according to the available resources and treatments [29-31]. The lowest tier stroke service can be built with low-cost equipment primarily focusing on well-trained interdisciplinary teams. Stroke centers should implement evidence-based treatment protocols, including thrombolytic therapy $[32,33]$.

Recommendations

1. Choose hospitals in each city or region to be established as stroke centers with organized emergency department and stroke unit care in accordance with local health authorities (e.g., Scandinavian countries, Spain, Germany, United States, United Kingdom, Russia);

2. Classify stroke centers choosing the model that best fits the region, state, or country and create an official certification process (e.g., United States, Germany, Austria, European certification efforts by ESO);

3. Provide training by specialized staff with standardized protocols;

4. Implement thrombolytic therapy for acute ischemic stroke;

5. Implement quality control instruments (database of all patients);

6. Alternatively, to solve the problem of overcrowded emergency rooms, the lack of beds in intensive care unit, and the lack of space to build acute stroke units, more general vascular units can be established that would include acute stroke management as has been done in Brazil. This is a specialized unit in the emergency room with a trained team to assist acute vascular disorders, including stroke, coronary syndromes, pulmonary embolism, and aortic diseases.

\section{Step 2: Development of Regional Systems of Emergency Stroke Care-}

Activating the prehospital emergency medical system and transportation to the designated stroke centers leads to a shorter delay in arrival at the hospital and better initial management. The training of ambulance teams and dispatchers in prehospital recognition of stroke as an emergency $[34,35]$ and the recognition of stroke signs increases the number of patients arriving earlier at hospital (e.g., Greater Los Angeles) [36]. Scientific statements recommend the development of regional systems of stroke care in which ambulances bring patients with acute stroke directly to stroke center hospitals to rapidly provide approved stroke therapies, improving the outcome of patients [37]

\section{Recommendations}

1. Training prehospital emergency medical systems teams to recognize stroke and to bring patients with acute stroke directly to designated stroke centers;

2. Develop regional networks of stroke care between prehospital emergency medical systems and stroke centers; and 
3. Whenever possible, use the same telephone number region wide to activate the prehospital emergency medical system (e.g., the European 112 campaign, 911 in the United States).

Step 3: Improving Stroke Awareness-Lack of recognition of stroke signs or lack of sense of urgency to seek help by the population is a major barrier for adequate stroke treatment. Stroke awareness campaigns can increase symptom identification, thus resulting in a decrease in the time from symptom onset to hospital arrival and increase in the number of patients who may receive appropriate interventions.

Recommendations

1. Promote evidence-based media campaigns providing public information about acute stroke signs and the urgency to call prehospital emergency medical systems;

2. Because stroke often renders patients themselves unable to recognize or communicate their symptoms, public education campaigns should inform not only at-risk individuals, but also family, friends, and on-scene witnesses to call the prehospital emergency medical system if they observe an individual having signs of a possible stroke.

A few successful examples from different parts of the world and different medical systems are described in Appendix 1 to illustrate how acute stroke treatment can be made more widely available.

\section{Brain Recovery and Rehabilitation: Harnessing the Regenerative Powers of the Brain and the Individual}

\section{Introduction}

After the acute period, a stroke will often affect a patient's life for many years. During the early days to weeks after a stroke, spontaneous repair events usually lead to some degree of behavioral recovery. The neurobiology of these repair events suggests several therapeutic targets to promote further recovery. Traditional rehabilitation is one of the therapeutic tools to augment the poststroke recovery process. A wide range of repair-based therapies is also in development [38].

Rehabilitation and repair is a relatively young and diverse field yet extends from the first days of inpatient care to ensuing care by rehabilitative specialists to years of chronic care in a range of settings. Current research topics span plasticity, normal learning, pharmacology, genetics, robotic engineering, occupational therapy, physical therapy, and speech therapy and growth in these areas will continue to improve rehabilitation [39].

Four steps for stroke rehabilitation/recovery therapies are considered subsequently. The goal of rehabilitation/ recovery stroke medicine is to have more patients achieving better recovery in the weeks after a stroke and experiencing less disability during the years that follow.

\section{Step 1: Translate Best Neuroscience, Including Animal and Human Studies, Into Poststroke Recovery Research and Patient Care}

Key Issues: The neurobiology of spontaneous recovery and central nervous system repair [40] suggests several potential therapeutic approaches that could improve patient outcome, but more research is needed. Current treatment options are limited. Although traditional rehabilitation medicine helps patients, a better understanding of its scientific basis could 
further increase its impact. Active research may also lead to design of new therapies that ultimately may win approval such as those using pharmacological, cell-based, electromagnetic, robotic, or neuroprosthetic approaches.

Recommendations

Increased basic and translational research is needed. A deeper insight into the neurobiology of poststroke recovery is required. The means by which principles of normal learning and development can be applied to stroke recovery need to be better understood [41]. Tools for measuring the biology of stroke recovery in humans are needed, from behavioral measures with defined psychometric properties to biomarkers such as for recording physiology of repair-related events [42]. Results of such research should be regularly compiled in both clinical and basic science State of the Art for Stroke Recovery Status Reports. This broad area of research may be best addressed by developing a group of Stroke Recovery Research Centers.

Translational studies are needed to determine the effects that various rehabilitation/ repair therapies have on recovery both as isolated therapies as well as in various combinations. A number of combination approaches can be envisioned, for example, traditional rehabilitation paired with a central nervous system stimulant, brain stimulation paired with a robotic therapy (with a single computer driving both), an angiogenic growth factor followed by a synaptogenic growth factor, or exercise therapy paired with motor imagery therapy. In this regard, traditional rehabilitation can be regarded as a key tool, in the therapeutic armamentarium for stroke recovery. Like with any medical therapy, the optimal timing, intensity, duration, and content of therapy needs to be continually refined using scientifically sound approaches. Some of these issues need to be clarified for individual therapies before combining into combination therapies. Specific to stroke recovery are issues such as defining the degree of task specificity for poststroke training. The impact of comorbidities, both prestroke and poststroke, needs consideration with a focus on identification of possible modifiable and nonmodifiable comorbidities.

\section{Step 2: The Practice of Poststroke Rehabilitation Needs to Be Standardized Based on Best Evidence}

Key Issues: Substantial data exist on the practice of poststroke rehabilitation [43]. As parallel research continues to refine the approaches, there is a need to apply currently existing knowledge to optimize patient outcome. Key issues include the organizational structure, timing, intensity, and task specificity of poststroke therapy [44]. Attention to community reintegration is also needed.

\section{Recommendations}

Detailed, standardized poststroke therapy protocols need to be developed and their practice associated with proper training. This should extend to transition to the community and then to a multiyear chronic phase of rehabilitation. Monetary and payment incentives must be redefined to drive implementation of these protocols. The lessons from published studies and best practices must be operationalized [45]. This can be partly achieved by improved benchmarking of processes, outcomes, and costs.

Medical school and postgraduate training should incorporate the protocols and best practices and should include suitable educational media and modules to support the implementation. Many of these solutions can be addressed by development of Stroke Recovery Research Centers. 


\section{Step 3: Develop Consensus on, Then Implementation of, Standardized Clinical and Surrogate Measurements}

Key Issues: The best standardized measures of behavior and outcomes after stroke need to be defined and then placed into clinical practice, at the same time continuing to generate appropriate research. These need to be used across rehabilitation systems and regions. These should be measured and communicated in a consistent manner. Standardized rater training needs to be developed for these measures.

Surrogate markers of treatment effect also are needed, including imaging (anatomic and functional), physiological, and biological (such as genetics). These might be used as predictive tools for outcome and thus be of value for triage; as entry criteria in clinical trials of repair-related therapies; or in evaluating treatment outcomes to guide clinical decisionmaking.

Achieving consensus on clinical measures and bio-markers in this context would be useful for clinical practice and also for developing clinical trials of therapies targeting stroke recovery.

\section{Recommendations}

Experts need to be gathered to discuss these issues and to propose unifying strategies to achieve rapid progress in the study of rehabilitation interventions. One possible mechanism would be an International Harmonization Conference, which would help achieve expert consensus on poststroke behavioral and clinical measures as well as on surrogate markers, as has been done in other neurological conditions. Development of Stroke Recovery Research Centers would be useful to achieve such consensus, for subsequent pilot testing of the recommendations, and for defining means for broader implementation.

Further research is needed to define the psychometric qualities and performance of proposed surrogate markers.

\section{Step 4: Target Repair-Related Processes in Clinical Research to Advance Stroke Recovery}

Key Issues: Available research suggests many strong candidates for therapies that are likely to improve poststroke recovery by targeting repair-related processes. However, clinical trials in this domain are few and often small in size. A significant need exists to design and execute clinical trials focused on stroke rehabilitation and repair.

Stroke rehabilitation/repair clinical trials need to be hypothesis-driven, properly designed, and appropriately powered with vertical integration of basic, clinical, and epidemiological disciplines. The clinical trial structure should extend beyond mere hypothesis testing to discovery and exploration, the latter being much needed in this expanding field with immense potential to help numerous patients with stroke.

Randomized clinical trials are the mainstay of examining candidate therapies. Additional research structures also might be used to further address these issues. Examples include innovative trial designs such as a cluster randomized design as well as shared databases.

Note that the impact of such trials will be maximized if paralleled by studies of clinical effectiveness and pertinent health economic topics.

Recommendations 
A Neurorecovery Consortium needs to be created consisting of academic (basic and clinical researchers, likely based at the Stroke Recovery Research Centers), industry, government research, clinicians, and payers with the mission being to define priorities and future actions for stroke recovery trials. Specific Stroke Rehabilitation/Recovery Conferences should be supported to address shared issues related to stroke recovery and rehabilitation.

Centralized strategic plans for brain recovery science should be developed, akin to the England Stroke Research Centers. Clinical trial networks should be developed to accelerate completion of stroke recovery clinical trials using cardiac disease or cancer cooperative groups as examples.

\section{Into the 21st Century: The Web, Technology and Communications, New Tools for Progress}

\section{Introduction}

Major reductions in the burden of stroke can be achieved by providing better public education. In many parts of the world, access to reliable medical information and even electricity is limited. The electronic means to disseminate health information (e.g., healthier lifestyle, risk factors, stroke symptoms, and emergency response) are available in industrialized countries, but less so in developing countries. There is a wide disparity in global internet penetration [46] according to geographic ( fig. 1) and demographic characteristics with older individuals less likely to access electronic information. Adoption of universal technology standards and worldwide unrestricted access to data will in part define how these disparities can be addressed. In the developed world, with the advent of high-bandwidth wireless delivery systems, there will be few regions without Internet access provided that sufficient resources are invested. In those parts of the world where connectivity is more limited, different strategies for knowledge dissemination and behavior change will need to be adapted to the available communication means (e.g., mobile phones, print, radio, television, word of mouth).

\section{Step 1: Worldwide Unrestricted Access to Information}

Education for the Public and Professionals: To reduce stroke risk, electronic mediaenabled tools can be used for self-assessment and motivation for self-management. These information portals can provide self-administered programs and/or interactions with professionals.

Support Groups: Lay organizations (e.g., church, community groups) are an underused resource that can provide insights into the types of support and problem-solving that are most needed by stroke survivors, including advice on financial resources, legal matters, and social benefits. Resources should be devoted to supporting these peer-to-peer networks with interfaces to reliable sources of health information.

Recommendations

The Public

To be free of bias, health information should be reviewed or provided by experts in stroke in collaboration with experts in public education without conflict of interest (e.g., government and nongovernment stroke-oriented health organizations) and delivered in a persuasive and understandable format consistent with principles of marketing and behavioral sciences as appropriate for the region.

Professionals 
Special task forces of these same organizations should prepare evidence-based online education for general practitioners, specialists, nurses, therapists, and other healthcare workers in multiple languages tailored to professional groups working in diverse surroundings. These electronic information clearinghouses should be accessible to health professionals worldwide and include interactive educational methods whenever possible. These materials should be adaptable to environments where access to electricity and electronic communications is limited. This material should also be available as a degree-based distance learning program for healthcare workers worldwide.

Citizens against Stroke

Communication resources and social networking tools should be tailored to support local stroke initiatives consisting of professionals, decision-makers, politicians, administrators, representatives of local industry and businesses together with lay people. All initiatives should be tailored to raise public awareness of stroke and to spread information on its prevention and management.

\section{Step 2: Better Access to Organized Care for All Patients With Stroke}

Diagnostics, Acute Care, and Rehabilitation: Evidence exists that advanced telemedicine communication technology for stroke ('telestroke') is beneficial where immediate access to stroke expertise is not available [47-50]. Telemedicine may help to provide stroke prevention, acute care, and rehabilitation services in remote regions [51] and smaller urban hospitals without stroke expertise and to extend clinical research into a broader global community. In addition, more innovative rehabilitatin therapies, which can be administered in areas and countries with limited resources, must be implemented to reduce inequalities of access to rehabilitation. Close collaboration of healthcare administrators, physicians, allied healthcare providers, basic scientists, and engineers is needed to develop and implement new rehabilitation paradigms.

Connecting Professionals and Patients: Electronic communications between patients and professionals have an enormous potential to enhance self-management of risk factors and promote healthier lifestyles (e.g., obtaining advice on medication use and adherence, prevention, follow-up laboratory test results, and medical problems through a virtual healthcare visit or an e-consultation (www.mayoclinic.org). Data management systems need to be developed to maximize the potential benefits of this emerging area and create manageable tools and actionable tasks for healthcare workers.

Recommendations

Leaders and key stakeholders (including patients) will need to embrace these new models of telemedicine and virtual patient-provider interactions that will permit access especially for patients who are disabled or live in geographically remote regions. A first step is to reduce barriers to telemedicineenabled practice to encourage broader access to high-quality stroke care and rapid treatment for acute stroke therapies. Development of novel technology-assisted rehabilitation methods should be encouraged.

Step 3: Build Centralized Electronic Archives and Registries-Electronic health records are critical for quick and reliable access to patient information, for effective communication of care plans between different providers and settings, and for reducing medical errors. Furthermore, providing citizens with the option of having access to their own personal health records may enhance their adherence to treatment recommendations. 
Electronic registries can help evaluate documentation of treatment practices, treatment efficacy and comparative effectiveness, and improve clinical management of patients with stroke. Registries such as Safe Implementation of Thrombolysis in Stroke [SITS]; www.acutestroke.org/) and those of Austria, Finland, Scotland, Sweden, the United Kingdom, and Japan and national quality improvement programs in the United States (www.stroke-association.org/presenter.jhtml?identifier=3002728) have improved stroke care by providing feedback, benchmarks, and sharing of best practices. Electronic resources should be developed to support the capture and analysis of patient-reported outcomes for clinical care and research.

\section{Recommendations}

All nations should pursue to develop national, interoperable electronic health record systems with the goal of supporting continuity of care through delivery of comprehensive medical information on demand at the point of care for all their citizens. Common data elements pertinent to stroke-relevant risk factors, treatments, and functional outcomes should be included in the electronic health record systems. Ideally, nations should collaborate to develop international standards for data format and description to support international integration.

Registries and Evaluation of Efficacy: All nations should participate in national or international stroke quality improvement programs or registries or develop their own programs if current models are not suitable for their population or environment to provide the highest quality stroke care.

\section{Fostering Cooperation among Stakeholders to Enhance Stroke Care}

\section{Introduction}

Interactions among major stakeholders in the stroke field such as large stroke organizations, government agencies, nongovernmental organizations, industry, and patient organizations can be mutually beneficial. Integrated activities among these groups can enhance patient care, the development and implementation of new therapies, and the dissemination of new and existing information. The following sections describe the activities/contributions of these 5 sectors and also provide 3 concrete suggestions of how to enhance mutually beneficial activities over the next several years.

Large Stroke Organizations and Nongovernmental Organizations-Stroke is a prototype disease for coordinated actions vertically (with other medical disciplines) as well as horizontally by interactions among stakeholder organizations, government, and industry. Large stroke organizations such as the WSO serve as a key component in these networks, providing important leadership roles in coordinating activities and in establishing stroke firmly on the global health agenda. Improved stroke management is crucially dependent on an effective organization in all aspects of care. The large stroke organizations should establish clear policies and provide recommendations through guidelines and other documents. The large stroke organizations also organize large scientific conferences providing a platform for scientific advances and interactions. Tackling the global burden of stroke constitutes a major health challenge.

The AHA formation of the American Stroke Association (ASA) 10 years ago and its evolution to date is an excellent example of how an NGO, in this case a voluntary health organization, can influence scientific discovery and the translation of science into guidelines and how it can then implement programs to support guideline adherence, to improve outcomes, to provide extensive provider and patient resources, and to advocate for system change. AHA/ASA's expertise as a convener of experts to develop consensus statements and 
guidelines, as a generator of patient and public education, and its field structure of staff and volunteers who implement its programs all contribute to its success.

Going forward organizations such as AHA/ASA and WSO will need to collaborate extensively with other large stroke organizations and nongovernmental organizations, government agencies, industry, and academia to further advancements in patient care and development of new therapies and approaches.

Government-The National Institute of Neurological Disorders and Stroke (NINDS) is committed to the development of better therapies to prevent stroke and to improve the outcome for patients with stroke. The NINDS Stroke Program Review Group [52] outlined the priority areas for research and NINDS looks forward to an exciting new era in stroke research. NINDS has a number of ongoing clinical trials that are evaluating novel prevention approaches, acute interventions, and recoveryenhancing strategies. In addition to drugs and devices, the science of behavioral change needs to target the promotion of healthy behaviors decades before the age-dependent risk of stroke starts its exponential ascent. The NINDS translational program works with and funds investigators and their industry partners to bring promising stroke therapies through preclinical development. The NINDS, however, faces a plethora of hurdles. Unfortunately, a number of important and expensive clinical stroke trials cannot be completed due to poor enrollment. A greater emphasis on Phase II studies should be considered to ensure that experimental therapies tested in rigorously conducted animal studies actually engage the intended biological target in patients.

Patient Organizations-Patient organizations range from small, informal, local support groups to large corporations with significant influence. Interactions between patient organizations and other organizations flow both ways. The purposes of these interactions are many and therefore this topic is quite complex. The triggers for interactions are generally of 3 types: (1) issues of clinical service and patient safety; (2) driving innovation and science; and (3) influencing business and healthcare economics. Patient organizations can be conduits for patients to influence healthcare organizations, government, industry, and academia. Processes may be ad hoc or organized. Actions may be taken proactively or reactively. Patient organizations can be vehicles for patients to be influenced by healthcare organizations, government, industry, and academia. Again, processes may be ad hoc or organized, and actions may be taken proactively or reactively.

Industry-Industry plays a vital role in the development and implementation of novel therapies directed at improving the prevention and treatment of stroke. Most new drug or device therapies are discovered by relevant companies or in-licensed from other sources. The company then performs the necessary preclinical steps to allow for the performance of clinical trials. Clinical trials performed by the company that demonstrate safety and efficacy of the new therapeutic agent can lead to regulatory approval, presuming an adequate data package. Industry thus provides a key link for stroke patient care, new and presumably improved therapeutic agents. Additionally, industry is an important source for the dissemination of new information about stroke to both physicians and the lay public. This task is performed by sponsorship of conferences, education seminars, and small group meetings for both professional and lay audiences. The content of these educational endeavors should be free of bias, providing balanced and educationally sound information for the intended audience.

Recommendations

Three specific recommendations to enhance cooperation among large stroke organizations, nongovernmental organizations, government, patient organizations, and industry are: 
(1) provide an appropriate mechanism for the various stakeholders to communicate with each other about their needs and goals; (2) enhance clinical research by having these entities provide input about unmet needs and how to develop and disseminate new therapies; and (3) enhance patient and physician education by jointly developing and implementing educational initiatives.

A method to achieve these recommendations and those of all aspects of this document is to establish a consensus working group of these stakeholders under the aegis of organizations such as the WSO/WFN to discuss develop and propose an overall agenda for stroke worldwide.

\section{Educating and Energizing Professionals, Patients, the Public and Policymakers}

\section{Part 1: Educating and Energizing Professionals and Patients}

Introduction-Detailed clinical stroke knowledge is increasingly important in Europe, North America, and other developed regions and subspecialty training focused on stroke prevention, acute care, and rehabilitation has been formalized [32, 53]. Stroke units have become common in developed countries. In poorer countries, especially in those classified as 'low income' by the World Bank, specialized care hardly exists [54]. A first step in improving stroke care globally is to improve the strokerelated education of care providers in developing countries.

There are mechanisms in place for distributing knowledge and education related to HIV/ AIDS, malaria, and other infectious diseases. These same models could be applied to stroke education.

Several organizations including the ASA, the ESO, and the WSO have educational and professional training web sites. For example, the WSO site is the World Stroke Academy (www.world-stroke-academy.org/). It is available globally and is free. It is endorsed and supported by other educational initiatives including those from the ASA and the ESO. Other programs such as those from the AHA/ASA (http://my.americanheart.org/professional/) and the ESO (www.strokeuniversity.com/) provide professional educational resources. Globally, there are insufficient numbers of physicians trained in stroke. Neuro-vascular Education and Training in Stroke Management and Acute Reperfusion Therapy (NET SMART) is a government-funded, evidence-based, online educational system (www.netsmartstroke.com/) offering programs to support the learning needs of advanced practice nurses (nurse practitioners and clinical nurse specialists). Stroke-educated nurses, more numerous than physicians, are capable of playing instrumental roles within telestroke networks [55]. In Europe, a downloadable eCME certificate can be obtained that is recognized by other programs such as the European Masters in Stroke Medicine (www.donau-uni.ac.at/en/ studium/strokemedicine/index.php).

The WSO's 'ABC of Stroke Management' program is directed to healthcare providers in developing countries. It is being used in China, South Africa, and Vietnam and is an effective tool for postgraduate medical training [56, 57]. In Vietnam, 6000 medical doctors have finished WSO-sponsored stroke training. Approaches for rapid and accurate diagnosis and the importance of prevention of complications are emphasized [58]. Improving the availability of effective medications throughout the world is critical. The use of telemedicine to extend stroke expertise to underserved areas may be possible [48]. The wider use of early mobilization and taskdependent rehabilitation to optimize long-term outcomes, including reintegration of patients with stroke into the family, workplace, and community, is an 
important goal. It is important to develop a concept of 'brain health' that can be promoted for primordial and secondary prevention.

Patient and bystander responses to stroke symptoms are often delayed [59] Patient-focused voluntary organizations have developed programs to increase the stroke knowledge of the general public, patients with stroke, and their families. The AHA/ASA along with the American Academy of Neurology and the American College of Emergency Physicians (GiveMe-5), the ESO, and the Stroke Alliance for Europe (SAFE) have developed informational brochures and advertisements for this purpose. It is important to further disseminate these materials as teaching aids in schools and communities.

\section{Recommendations}

Step 1: Increase education directed at professionals including healthcare providers on a global scale by using on-site and website stroke teaching programs that are integrated into the medical education curricula. Recommendations should be based on a 'brain health' concept that enables promotion of preventive measures. The aim is to make professional specialized care available to patients with stroke throughout the world within the next decade.

Step 2: Further develop national health education programs offered for stroke survivors and their families. These programs should be offered in schools and communities under the leadership of the scientific organizations such as the WSO, the AHA/ ASA, the ESO, and other regional organizations. The aim is to improve stroke prevention and the public's recognition and response to stroke symptoms.

\section{Part 2: Educating and Energizing the Public and Policymakers}

Introduction-Worldwide efforts to increase knowledge and concern about stroke, its prevention, treatment opportunities, and outcomes have also focused on politicians and key opinion leaders. The role of governmental policy on stroke research and care is increasingly recognized.

In the United States, advocacy efforts have largely been directed at increasing or at least sustaining funding for research supported by the NIH [60]. Advocacy, in part, led to NIH Progress Review Groups aimed at identifying targets and strategies for stroke-related research. In addition, national advocacy efforts have supported cardiovascular and stroke prevention activities of the CDC. Specific targets included support of Food and Drug Administration oversight of tobacco products. Within states, advocacy has been aimed at improving the organization of the delivery of stroke-related health care [31]. Individual states have established stroke task forces or legislative committees focused on stroke care issues such as assessments by emergency responders, transport of patients with stroke to the nearest appropriate hospital, identification of primary stroke centers and acute stroke treatment-capable hospitals, and the use of telemedicine. Legislation to prevent cigarette smoking in indoor public spaces has been enacted in several states.

Educating the public about stroke risk factors, prevention, and response has been challenging. Public knowledge about stroke in the United States continues to be poor, particularly in minority communities [61, 62] Recently, the ASA, American College of Emergency Physicians, and American Academy of Neurology began a uniform education campaign, 'Give Me 5,'aimed at improving recognition of stroke symptoms. The ASA Power to End Stroke program focuses on blacks, who have approximately twice the risk compared with white Americans. 'You're the Cure' is the AHA/ASA grassroots advocacy network. Through 'You're the Cure,' thousands of advocates can be mobilized to support specific pieces of legislation or programs affecting stroke through targeted e-mails, phone 
calls, and letters to relevant policymakers. Although a great deal has been accomplished, much remains to be done.

The European Parliament founded the SAFE in 2004, which includes representatives from 17 countries [63]. In Europe, policymakers have become engaged in the European Union by activities from the European Brain Council, the ESO jointly with the European Stroke Conference, and the SAFE movement. Topics include the promotion of awareness of strokerelated health costs [64] and the large discrepancies between eastern and western Europe, including the much higher prevalence of risk factors and stroke in eastern Europe.

European specialist groups have lobbied for increased funding from the European Science Foundation and led to a European Stroke Workshop in Brussels hosted by the European Commission. The resulting European Stroke Network links stroke research from bench to bedside [65]. New initiatives ('Strike Out Stroke'2009) address the general public as well as members of the European Parliament focusing on problems related to the use of anticoagulants for patients with stroke.

\section{Recommendations}

Step 3: Increase funding for public education and research supported by regional and national agencies. Continue support for advocacy aimed at improving the organization of the delivery of stroke-related health care based on evidencebased recommendations addressing gaps in the care delivery system.

Step 4: Educate and inform the general public about stroke risk factors, prevention, and response. Use best practices such as 'Give Me 5,'aimed at improving recognition of stroke symptoms, the ASA's 'You're the Cure' advocacy program and the 'Strike Out Stroke' campaign in Europe.

\section{Summary}

To accelerate progress in stroke, we need to reach beyond it scientifically, conceptually, and pragmatically.

Scientifically the solutions lie beyond our limited models. All the major neurological brain diseases share common mechanisms such as inflammation, apoptosis, mitochondrial damage, oxidative stress, excitotoxicity, and neurotransmitter failure [66]. By and large these mechanisms are studied in relation to individual diseases, not from a biological, evolutionary, or integrated viewpoint. A close study of the development of the nervous system may hold many clues as to how the brain repairs itself. Moreover, development and aging may to some extent be mirror images of each other. Stroke in the neonatal brain [67], children, and women $[68,69]$, has special features that need to be understood and addressed.

Our focus has been on lesions in the brain. Aging and the complex interaction of genetics, epigenetics, and environment and the occurrence of concomitant pathology render individuals' brains unique. For example, cerebral infarcts shrink and the inflammation subsides with time. The opposite occurs experimentally in the presence of amyloid [70] Given that several common neurological conditions share the same mechanisms, a systematic approach may produce therapeutic targets that would be of benefit to more than one disease. It matters not only what lesion, but whose brain.

Conceptually we need to think not only of dramatic strokes of sudden onset, sometimes heralded by sudden losses of speech, sight, movement, or feeling, but of sub-clinical strokes, the most prevalent type of cerebrovascular disease identifiable by subtle cognitive dysfunction, usually a change in executive function [12]. Moreover, in the elderly brain, 
amyloid deposition and Alzheimer lesions may coexist and at times interact with the vascular lesions.

Pragmatically we need to realize that if we are to become more effective in the diagnosis, treatment, rehabilitation, and prevention of stroke, we have to reach beyond our hospitals and clinics into the community, other disciplines, and the public and a larger part of the world.

We need to survey, systematize, and synergize what we do. We need to survey broadly, systematically, and specifically what we know of basic brain mechanisms of disease. We need to become aware of other models such as infectious diseases, which often has an integrated, epide-miological, clinical, and basic science approach.

In terms of acute care and rehabilitation, an organized approach seems to have been the key to the many advances. Although countries like Spain have a national stroke strategy and effective regional programs such as those of Catalonia [71] and Madrid [72], the majority of countries do not. Stroke unit care should be considered a treatment/ intervention in itself similar to any pharmacological treatment or a surgical procedure. There may well be other models such as trauma that may provide useful parallels and lessons.

Systematization and evaluation has been a key in many of the advances that have occurred in stroke in the past 4 decades. A prototype has been the randomized clinical trial, in which a hypothesis is tested according to prospectively agreed protocols, the collection of the data monitored, and the results evaluated. Randomized clinical trials are but 1 example of the more generic principles.

We need to reach beyond North America, western Europe, and Japan, where most clinical trials have been performed. Other parts of the world are creating infrastructures that make them capable of participating in clinical trials and other studies that can accelerate finding the answers to many common problems. The Extracranial- Intracranial (EC/IC) Bypass Study [73] was an early example of how an international randomized clinical trial could reach an answer much more quickly than if it had been done in 1 country alone. More recently we saw the example of the first proof of tissue plasminogen activator effectiveness in stroke being demonstrated in an American study [4], whereas the extension of the time window was recently shown by a European study [74].

We need to become imaginative in designing multiple types of clinical trials, from active registries to simple and more complex randomized clinical trials. The idea would be that everything that is done in relation to stroke becomes part of some evaluation. An important aspect of any evaluation is standardization with a need to make minimum common definitions of important items in a protocol so that databases can be made compatible and larger volumes of information can become available for analysis, model-building, and testing.

At the moment, we have a glut of guidelines but not enough guidance or guides [75]. Most guidelines are developed on the basis of the level of evidence, but little attention is devoted to the relative impact of specific items. Not all are of equal value [76]. We need to evaluate and rank the relative value of each activity in terms of return per unit investment of time, resources, or both [77]. The comparative effectiveness research thus generated would improve clinical decision-making and lead to better allocation of scarce medical resources.

Stroke is no longer a disease of affluence. Approximately $87 \%$ of the 5.7 million deaths annually attributable to stroke occur in low-income and middle-income countries [78]. The risk factors like hypertension, diabetes, and obesity are assuming epidemic proportions. 
Some 285 million people worldwide will live with diabetes in 2010, $70 \%$ of whom will live in developing countries [79]. Moreover, by 2050, the population aged: 60 years is expected almost to triple, increasing to 1.6 billion in the developing countries [80].

The Institute of Medicine's recent report recommends building evidence-based, locally relevant solutions by improving global collaboration among stakeholders to promote cardiovascular health in the developing world [81]. Aligning chronic disease priorities with other health and development priorities has the potential to synergistically improve economic and health status.

There is much value in doing the simple things right in terms of prevention. 'Death in old age is inevitable, but most deaths before old age are avoidable' [82]. Hypertension is the single most powerful and prevalent risk factor for ischemic and hemorrhagic stroke and vascular cognitive impairment and yet too often it remains unrecognized or untreated. Blood pressure control has the greatest potential for stroke prevention.

The concept of 'vascular health' or 'brain health' needs to be promoted. Because atherosclerosis starts early in life, the preventive efforts should target children, youth, and mothers. Everyone needs to be involved at all stages of prevention with an emphasis on healthy living and creating an environment that nurtures it.

Finally, we need to synergize with vertical integration of basic sciences, clinical sciences, and population approaches. The digital age provides wonderful opportunities for integrating and evaluating all aspects of our activities.

\section{Next Steps}

The immediate need is to pursue specific recommendations:

1. A systematic review of all that is known of basic brain mechanisms of injury and repair along the life cycle. This can be accomplished at several levels: (a) review of the existing literature; (b) making it a topic of ongoing scientific conferences such as the Princeton Conference or as a priority setting exercise of funding agencies [52]; and (c) organize a highly interactive synergium with participation of scientists, clinicians, pharmaceutical companies, and health regulators. The synergium should be broad enough that each mechanism can be examined in light of several diseases.

2. To organize a working group that will recommend a minimum set of data points to be collected on all patients with stroke or those with potential stroke. This already has been done for capturing vascular cognitive impairment from the epidemiological, clinical, neuropsychological, imaging, and experimental viewpoint [83]. It may be that it simply needs modification or adaptation.

3. Another working group could evaluate the relative advantages and disadvantages of different clinical trials, including novel approaches to use registries to evaluate different diagnoses and treatments.

4. The WSO already has a working group on guidelines that could be enlarged and asked to prioritize them with a simple method of evaluating their impact.

5. A working group on surveying and evaluating stroke education with methods of integrating and credentialing those who engage in stroke work. 
6. Develop nodular models of comprehensive stroke care, rehabilitation, and prevention on the principle that some components are essential but that they need to be adapted in the community where they are to be implemented. Professional education including a more comprehensive education on stroke and stroke recovery for medical school curricula as well as residency and fellowship training. The latter may be best done at Centers of Stroke Emphasis or Stroke Recovery Research Centers.

7. Support the efforts of Raad Shakir, Secretary General of the World Federation of Neurology and Chair of the Expert Committee advising on Diseases of the Nervous System for the International Classification of Diseases [84] (ICD-11), and Bo Norrving, President of the WSO, to reclassify stroke from a cardiovascular to a disease of the nervous system and vascular dementia from mental diseases to brain diseases.

8. Precompetitive stroke recovery initiative: We should consider precompetitive consortia for stroke recovery that is similar to that currently in operation for Alzheimer disease - the Alzheimer's Disease Neuroimaging Initiative (ADNI) [85]. Perhaps collectively (academia, industry, and government), we could create a 'SRNI' (stroke recovery neuroimaging initiative), a precompetitive consortia to enroll and carefully study patients for the natural history of stroke recovery: imaging, scales, and biological samples. The groups involved would agree to what end points should be studied. This would help not only in understanding the pathophysiology of stroke, but also in the design of clinical trials to ensure that the proper end points are used and that they are powered appropriately.

9. Educate and energize professionals, patients, the public, and policymakers by using a 'brain health' concept that enables promotion of preventive measures.

10. Organize a working group that will oversee these and other initiatives that may arise from the recommendations of the synergium.

\section{Conclusion}

We have come a long way, but we have even further to go.The progressive transformation of our field in the past 40 years, the accelerated pace of science, and the growing need for our contributions will assure that the next 4 decades will prove even more fruitful than the last.

\section{Acknowledgments}

We thank Gary Houser and his Stroke Group for expert help in organizing the Synergium. Warm thanks to Yvette Ballantyne and the AHA staff for help with the organization and registration for the Synergium. We thank the supporting organizations of the Syn-ergium: AHA/ASA, World Federation of Neurology, WSO, ESO, European Stroke Conference, Canadian Stroke Network, Heart \& Stroke Foundation Centre for Stroke Recovery, and Lippincott Williams \& Wilkins. The views and conclusions of the synergium are that of the participants and contributors and not necessarily those of the supporting organizations.

A special thank you to Professor Michael Hennerici, Editor of Cerebrovascular Diseases and Chairman of the Scientific Program Committees of the European Stroke Conference, for his material support and spirit of cooperation exemplified by the joint and simultaneous publication of this article in the respective journals that he and the first author edit.

Mona Tiwari, research and editorial assistant, was immensely helpful in producing the final document. Thank you! 
The Synergium authors appreciate the input of Drs Walter Ko-roshetz and Petra Kaufmann as well as the financial support of the National Institute of Neurological Disorders and Stroke.

We are grateful to Christina O'Callaghan and Drs David Cechet-to, Ángel Chamorro, Lu Chuanzhen, Robert Cote, Antoni Davalos, Bart Demaerschalk, Valentin Fuster, Moira Kapral, Gian Luigi Lenzi, Mary Lewis, MingMing Ning, John W. Norris, Gustavo Saposnik, Exuperio Diez Tejedor, Danilo Toni, Peggy Vandervoort, Tony Vandervoort, and Mohammad Wasay for useful comments and stimulating discussion. We thank Jennifer Neisse, BS, of InTouch Health who contributed to the section on the development of public health communication strategies using traditional and newer strategies.

\section{References}

1. Kannel WB, Wolf PA, Verter J, McNamara PM. Epidemiologic assessment of the role of blood pressure in stroke.The Framingham study. JAMA. 1970; 12:301-310. 214. [PubMed: 5469068]

2. Canadian Cooperative Study Group. A randomized trial of aspirin and sulfinpyrazone in threatened stroke. N Engl J Med. 1978; 299:53-59. [PubMed: 351394]

3. Norris JW, Hachinski VC. Intensive care management of stroke patients. Stroke. 1976; 7:573-577. [PubMed: 1006732]

4. The National Institute of Neurological Disorders and Stroke rt-PA Stroke Study Group. Tissue plasminogen activator for acute ischaemic stroke. N Engl J Med. 1995; 333:1581-1587. [PubMed: 7477192]

5. Millikan CH. Stroke: 970-1977. Stroke. 2001; 32:3-5. [PubMed: 11136905]

6. McDowell FH. Stroke: 30 years of progress:1977-1981. Stroke. 2001; 32:595-596. [PubMed: 11239173]

7. Barnett HJ. Stroke: 30 years of progress:1982-1987. Stroke. 2001; 32:1051-1053. [PubMed: 11340208]

8. Reinmuth OM. Stroke:30 years of progress: 1987-1991. Stroke. 2001; 32:2211-2212. [PubMed: 11588302]

9. Dyken ML. Stroke:30 years of progress: 1992-2000. Stroke. 2001; 32:2730-2733.

10. Anderson BE, Rafferty AP, Lyon-Callo S, Fussman C, Reeves MJ. Knowledge of tissue plasminogen activator for acute stroke among Michigan adults. Stroke. 2009; 40:2564-2567. [PubMed: 19407229]

11. Hackam DG, Kapral MK, Wang JT, Fang J, Hachinski V. Most stroke patients do not get a warning: a population-based cohort study. Neurology. 2009; 73:1074-1076. [PubMed: 19786701]

12. Leary MC, Saver JF. Annual incidence of first silent stroke in the United States: a preliminary estimate. Cerebrovasc Dis. 2003; 16:280-285. [PubMed: 12865617]

13. Donnan G. The 2007 Feinberg lecture: a new road map for neuroprotection. Stroke. 2008; 39:242. [PubMed: 18048866]

14. Fisher M, Feuerstein G, Howells DW, Hurn PD, Kent TA, Savitz SI, Lo EH. Update of the stroke therapy academic industry round-table preclinical recommendations. Stroke. 2009; 40:2244-2250. [PubMed: 19246690]

15. Howells D, Donnan G. Where will the next generation of stroke treatments come from? PLoS Medicine. 2010; 7:e1000224. [PubMed: 20208999]

16. Dobkin B. Collaborative models for translational neuroscience and rehabilitation research. Neurorehabil Neural Repair. 2009; 23:633-640. [PubMed: 19541919]

17. Villoslada P, Steinman L, Baranzini S. Systems biology and its application to the understanding of neurological diseases. Ann Neurol. 2009; 65:124-139. [PubMed: 19260029]

18. Pitman J, DasGupta S, Krashes M, Leung B, Perrat P, Waddell S. There are many ways to train a fly. Fly (Austin). 2009; 3:3-9. [PubMed: 19164943]

19. Pfrieger F. Roles of glial cells in synapse development. Cell Mol Life Sci. 2009; 66:2037-2047. [PubMed: 19308323]

20. Huang H, Zon L. Regulation of stem cells in the zebra fish hematopoietic system. Cold Spring Harb Symp Quant Biol. 2008; 73:111-118. [PubMed: 19022765]

21. Chiuve SE, Rexrode KM, Spiegelman D, Logroscino G, Manson JE, Rimm EB. Primary prevention of stroke by healthy lifestyle. Circulation. 2008; 118:947-954. [PubMed: 18697819] 
22. Gorelick PB. Primary prevention of stroke. Impact of healthy lifestyle. Circulation. 2008; 118:904906.

23. Thompson CS, Hakim AM. Living beyond our physiological means:small vessel disease of the brain is an expression of a systemic failure in arteriolar function: a unifying hypothesis. Stroke. 2009; 40:e322-e330. [PubMed: 19228835]

24. Beagelhole R, Ebrhim S, Reddy S, Voute J, Leeder S. for the Chronic Disease Action Group:Prevention of chronic diseases: a call to action. Lancet. 2007; 370:2152-2157. [PubMed: 18063026]

25. Global Noncommunicable Disease Network (NCDnet). [Accessed March 25,2010] World Health Organization. Available at: www.who.int/ncdnet/about/en/.

26. Yusuf S, Pais P, Afzal R, Xavier D, Teo K, Eikelboom J, Sigamani A, Mohan V, Gupta R, Thomas $\mathrm{N}$. Effects of a polypill (Polycap) on risk factors in middle-aged individuals without cardiovascular disease (TIPS): a phase II, double-blind, randomized trial. Lancet. 2009; 373:1341-1351. [PubMed: 19339045]

27. US Department of Health and Human Services. [Accessed March 15,2010] Making Health Communication Programs Work. 2002. Available at: www.cancer.gov/pinkbook.

28. Kaste M, Boysen G, Indredavik B, Norrving B. Stroke unit care in Scandinavian countries. Int J Stroke. 2006; 1:44. [PubMed: 18706074]

29. Alberts MJ, Hademenos G, Latchaw RE, Jagoda A, Marler JR, Mayberg MR, Starke RD, Todd HW, Viste KM, Girgus M, Shephard T, Emr M, Shwayder P, Walker MD. Recommendations for the establishment of primary stroke centers. Brain Attack Coalition. JAMA. 2000; 283:3102-3109. [PubMed: 10865305]

30. Alberts MJ, Latchaw RE, Selman WR, Shephard T, Hadley MN, Brass LM, Koroshetz W, Marler JR, Booss J, Zorowitz RD, Croft JB, Magnis E, Mulligan D, Jagoda A, O'Connor R, Cawley CM, Connors JJ, Rose-DeRenzy JA, Emr M, Warren M, Walker MD. Recommendations for comprehensive stroke centers: a consensus statement from the Brain Attack Coalition. Stroke. 2005; 36:1597-1616. [PubMed: 15961715]

31. Schwamm LH, Pancioli A, Acker JE III, Goldstein LB, Zorowitz RD, Shephard TJ, Moyer P, Gorman M, Johnston SC, Duncan PW, Gorelick P, Frank J, Stranne SK, Smith R, Federspiel W, Horton KB, Magnis E, Adams RJ. Recommendations for the establishment of stroke systems of care: recommendations from the American Stroke Association's task force on the development of stroke systems. Stroke. 2005; 36:690-703. [PubMed: 15689577]

32. European Stroke Organization (ESO) Executive Committee; ESO Writing Committee. Guidelines for management of ischaemic stroke and transient ischaemic attack 2008. Cerebrovasc Dis. 2008; 25:457-507. [PubMed: 18477843]

33. Schwamm LH, Fonarow GC, Reeves MJ, Pan W, Frankel MR, Smith EE, Ellrodt G, Cannon CP, Liang L, Peterson E, Labresh KA. Get with the Guidelines-Stroke is associated with sustained improvement in care for patients hospitalized with acute stroke or transient ischemic attack. Circulation. 2009; 119:107-115. [PubMed: 19075103]

34. Ramanujam P, Guluma KZ, Castillo EM, Chacon M, Jensen MB, Patel E, Linnick W, Dunford JV. Accuracy of stroke recognition by emergency medical dispatchers and paramedics - San Diego experience. Prehosp Emerg Care. 2008; 12:307-313. [PubMed: 18584497]

35. Buck BH, Starkman S, Eckstein M, Kidwell CS, Haines J, Huang R, Colby D, Saver JL. Dispatcher recognition of stroke using the National Academy Medical Priority Dispatch System. Stroke. 2009; 40:2027-2030. [PubMed: 19390065]

36. Kidwell CS, Starkman S, Eckstein M, Weems K, Saver JL. Identifying stroke in the field. Prospective validation of the Los Angeles Prehospital Stroke Screen (LAPSS). Stroke. 2000; 31:71-76. [PubMed: 10625718]

37. Acker JE III, Pancioli AM, Crocco TJ, Eckstein MK, Jauch EC, Larrabee H, Meltzer NM, Mergendahl WC, Munn JW, Prentiss SM, Sand C, Saver JL, Eigel B, Gilpin BR, Schoeberl M, Solis P, Bailey JR, Horton KB, Stranne SK. Implementation strategies for emergency medical services within stroke systems of care: a policy statement from the American Heart Association/ American Stroke Association expert panel on Emergency Medical Services Systems and the Stroke Council. Stroke. 2007; 38:3097-3115. [PubMed: 17901393] 
38. Cramer SC. Repairing the human brain after stroke. II. Restorative therapies. Ann Neurol. 2008; 63:549-560. [PubMed: 18481291]

39. Nudo RJ. Plasticity. NeuroRx. 2006; 3:420-427. [PubMed: 17012055]

40. Murphy TH, Corbett D. Plasticity during stroke recovery: from synapse to behaviour. Nat Rev Neurosci. 2009; 10:861-872. [PubMed: 19888284]

41. Kleim JA, Jones TA. Principles of experience-dependent neural plasticity:implications for rehabilitation after brain damage. J Speech Lang Hear Res. 2008; 51:S225-S239. [PubMed: 18230848]

42. Milot MH, Cramer SC. Biomarkers of recovery after stroke. Curr Opin Neurol. 2008; 21:654-659. [PubMed: 18989108]

43. Teasell R, Foley N, Salter K, Bhogal S, Jutai J, Speechley M. Evidence-based review of stroke rehabilitation: executive summary, 12th edition. Top Stroke Rehabil. 2009; 16:463-488. [PubMed: 20139049]

44. Teasell R, Meyer MJ, McClure A, Pan C, Murie-Fernandez M, Foley N, Salter K. Stroke rehabilitation: an international perspective. Top Stroke Rehabil. 2009; 16:44-56. [PubMed: 19443347]

45. Teasell R, Meyer MJ, Foley N, Salter K, Willems D. Stroke rehabilitation in Canada: a work in progress. Top Stroke Rehabil. 2009; 16:11-19. [PubMed: 19443343]

46. World Internet penetration rates by geographic region. [Accessed March 25, 2010] Internet world stats. 2009. Available at: www.internetworldstats.com/stats.htm.

47. Schwamm LH, Hollo way RG, Amarenco P, Audebert HJ, Bakas T, Chumbler NR, Handschu R, Jauch EC, Knight WAT, Levine SR, Mayberg M, Meyer BC, Meyers PM, Skal-abrin E, Wechsler LR. A review of the evidence for the use of telemedicine within stroke systems of care: a scientific statement from the American Heart Association/ American Stroke Association. Stroke. 2009; 40:2616-2634. [PubMed: 19423852]

48. Schwamm LH, Audebert HJ, Amarenco P, Chumbler NR, Frankel MR, George MG, Gorelick PB, Horton KB, Kaste M, Lackland DT, Levine SR, Meyer BC, Meyers PM, Patterson V, Stranne SK, White CJ. Recommendations for the implementation of telemedicine within stroke systems of care: a policy statement from the American Heart Association. Stroke. 2009; 40:2635-2660. [PubMed: 19423851]

49. Tatlisumak T, Soinila S, Kaste M. Telestroke networking offers multiple benefits beyond thrombolysis. Cerebrovasc Dis. 2009; 27(suppl 4):21-27. [PubMed: 19546538]

50. Demaerschalk BM, Miley ML, Kiernan TE, Bobrow BJ, Corday DA, Wellik KE, Aguilar MI, Ingall TJ, Dodick DW, Brazdys K, Koch TC, Ward MP, Richemont PC. STARR Coinvestigators: Stroke telemedicine. Mayo Clin Proc. 2009; 84:53-64. [PubMed: 19121244]

51. Miley ML, Demaerschalk BM, Olmstead NL, Kiernan TE, Corday DA, Chikani V, Bobrow BJ. The state of emergency stroke resources and care in rural Arizona: a platform for telemedicine. Telemed J E Health. 2009; 15:691-699. [PubMed: 19694588]

52. Grotta JC, Jacobs TP, Koroshetz WJ, Moskowitz MA. Stroke program review group: an interim report. Stroke. 2008; 39:1364-1370. [PubMed: 18309142]

53. Adams HP Jr, del Zoppo G, Alberts MJ, Bhatt DI, Brass L, Furlan A, Grubb RL, Higashida RT, Jauch EC, Kidwell C, Lyden PD, Morgen-stern LB, Qureshi AI, Rosenwasser RH, Scott PA, Wijdicks EFM. Guidelines for the early management of adults with ischemic stroke. Stroke. 2007; 38:1655-1711. [PubMed: 17431204]

54. Brainin M, Teuschl Y, Kalra L. Acute treatment and long-term management of stroke in developing countries. Lancet Neurol. 2007; 6:553-561. [PubMed: 17509490]

55. Kiernan TEJ, Demaerschalk BM. Nursing roles within a stroke telemedicine network. Journal of Central Nervous System Disease. 2010; 2:1-7.

56. Brainin M. The I International Conference on Advancement and Recommendations for Stroke Management (ICARSM) held in Chengdu, China. Int J Stroke. 2007; 2:231. [PubMed: 18705952]

57. Brainin M. Introductory report: WSO Education Committee 2008. Int J Stroke. 2009; 4:148. [PubMed: 19659811] 
58. Trapl M, Enderle P, Nowotny M, Teuschl Y, Matz K, Dachenhausen A, Brainin M. Dysphagia bedside screening for acute-stroke patients: the Gugging Swallowing Screen. Stroke. 2007; 38:2948-2952. [PubMed: 17885261]

59. Teuschl Y, Brainin M. Stroke education: discrepancies among factors influencing prehospital delay and stroke knowledge. Int J Stroke. 2010 In press.

60. Goldstein LB. Reducing death and disability from stroke. The role of governmental advocacy. Stroke. 2008; 39:2898-2901. [PubMed: 18688009]

61. Fang J, Keenan NL, Ayla C, Dai S, Merritt R, Denny CH. Awareness of stroke warning symptoms - 13 states and the District of Columbia, 2005. MMWR Morbid Mortal Wkly Rep. 2008; 57:481485.

62. Goldstein LB, Silberberg M, McMiller Y, Yaggy SD. Stroke-related knowledge among uninsured Latino immigrants in Durham County, North Carolina. J Stroke Cerebrovasc Dis. 2009; 18:229_ 231. [PubMed: 19426895]

63. Stroke alliance for Europe. [Accessed January 5, 2010] Member organizations. Available at:www.safestroke.org/ membership/member-organisations.aspx.

64. Andlin-Sobocki P, Jönsson B, Wittchen H-U, Olesen J. Cost of disorders of the brain in Europe. Eur J Neurol. 2005; 12(suppl 1):1-27. [PubMed: 15877774]

65. The European Stroke network. [Accessed January 5, 2010] Available at: www.europeanstrokenetwork.eu/.

66. Hachinski V. The 2005 Thomas Willis Lecture. Stroke and vascular cognitive impairment. A transdisciplinary, translational and transactional approach. Stroke. 2007; 38:1396-1403. [PubMed: 17347469]

67. Ferriero DM. Neonatal brain injury. N Engl J Med. 2004; 351:1985-1995. [PubMed: 15525724]

68. Bushnell CD, Hurn P, Colton C, Miller VM, del Zoppo G, Elkind MS, Stern B, Herrington D, Ford-Lynch G, Gorelick P, James A, Brown CM, Choi E, Bray P, Newby LK, Goldstein LB, Simpkins J. Advancing the study of stroke in women: summary and recommendations for future research from an NINDS-sponsored multidisciplinary working group. Stroke. 2006; 37:23872399. [PubMed: 16857945]

69. Kurth T, Bousser MG. Stroke in women: an evolving topic. Stroke. 2009; 40:1027-1028. [PubMed: 19211478]

70. Whitehead SN, Cheng G, Hachinski VC, Cechetto DF. Progressive increase in infarct size, neuroinflammation, and cognitive deficits in the presence of high levels of amyloid. Stroke. 2007; 38:3245-3250. [PubMed: 17962591]

71. Abilleira S, Gallofré M, Ribera A, Sánchez E, Tresserras R. Quality of in-hospital stroke care according to evidence-based performance measures: results from the first audit of stroke, Catalonia, Spain. Stroke. 2009; 40:1433-1438. [PubMed: 19213949]

72. de Leciñana-Cases MA, Gil-Núñez A, Díez-Tejedor E. Relevance of stroke code, stroke unit and stroke networks in organization of acute stroke care - the Madrid acute stroke care program. Cerebrovasc Dis 2009. 27(suppl 1):140-147.

73. Barnett HJ, Sackett D, Taylor DW, Haynes B, Peerless SJ, Meissner I, Hachinski V, Fox A. Are the results of the extracranial-intracranial bypass trial generalizable? N Engl J Med. 1987; 316:820-824. [PubMed: 3821825]

74. Bluhmki E, Chamorro A, Dávalos A, Machnig T, Sauce C, Wahlgren N, Wardlaw J, Hacke W. Stroke treatment with alteplase given $3.0-4.5 \mathrm{~h}$ after onset of acute ischaemic stroke (ECASS III): additional outcomes and subgroup analysis of a randomized controlled trial. Lancet Neurol. 2009; 8:1095-1102. [PubMed: 19850525]

75. Bayley M, Lindsay P, Hellings C, Woodbury E, Phillips S. Canadian Stroke Strategy (a joint initiative of the Canadian Stroke Network and the Heart and Stroke Foundation of Canada). Balancing evidence and opinion in stroke care: the 2008 best practice recommendations. CMAJ. 2008; 179:1247-1249. [PubMed: 19047599]

76. Norrving B, Wester P, Stibrant Sunnerhagen K, Sven Terent A, Sohlberg A, Berggren F, Wester PO, Asplund K. Beyond conventional stroke guidelines: setting priorities. Stroke. 2007; 38:21852190. [PubMed: 17540970]

77. Hachinski V. Stroke: 30 years of progress. Stroke. 2001; 32:1. [PubMed: 11136903] 
78. Strong K, Mathers C, Bonita R. Preventing stroke: saving lives around the world. Lancet Neurol. 2007; 6:182-187. [PubMed: 17239805]

79. International Diabetes Federation. The Diabetes Atlas. Brussels: IDF; 2010.

80. Population Division, Department of Economic and Social Affairs, United Nations. [Accessed April 6, 2010] World Population Ageing. 2009. Available at: www.un.org/esa/population/publications/ WPA2009/WPA2009_WorkingPaper.pdf.

81. Institute of Medicine. Promoting Cardiovascular Health in the Developing World:A Critical Challenge to Achieve Global Health. Washington, DC: The National Academies Press; 2010.

82. McManus, R. [Accessed March 30, 2010] Peto says halving premature death rate is an achievable goal. The NIH Record. 2002;LIV(18). Available at: http://nihrecord.od.nih.gov/newsletters/ 09_03_2002/story02.htm.

83. Hachinski V, Iadecola C, Petersen RC, Breteler MM, Nyenhuis DL, Black SE, Powers WJ, DeCarli C, Merino JG, Kalaria RN, Vinters HV, Holtzman DM, Rosenberg GA, Wallin A, Dichgans M, Marler JR, Leblanc GG. National Institute of Neurological Disorders and Stroke Canadian Stroke Network vascular cognitive impairment harmonization standards. Stroke. 2006; 37:2220-2241. [PubMed: 16917086]

84. Bergen DC. WFN, WHO take on ICD-10 revisions. World Neurology. 2009; 24:1.

85. Miller G. Alzheimer's biomarker initiative hits its stride. Longitudinal Alzheimer's studies go global. Science. 2009; 326:386-389. [PubMed: 19833956]

\section{References}

1. Alberts MJ, Hademenos G, Latchaw RE, Jagoda A, Marler JR, Mayberg MR, Starke RD, Todd HW, Viste KM, Girgus M, Shephard T, Emr M, Shwayder P, Walker MD. Recommendations for the establishment of primary stroke centers. Brain attack coalition. JAMA. 2000; 283:3102-3109. [PubMed: 10865305]

2. Alberts MJ, Latchaw RE, Selman WR, Shephard T, Hadley MN, Brass LM, Koroshetz W, Marler JR, Booss J, Zorowitz RD, Croft JB, Magnis E, Mulligan D, Jagoda A, O'Connor R, Cawley CM, Connors JJ, Rose-DeRenzy JA, Emr M, Warren M, Walker MD. Recommendations for comprehensive stroke centers: a consensus statement from the brain attack coalition. Stroke. 2005; 36:1597-1616. [PubMed: 15961715]

3. Kidwell CS, Starkman S, Eckstein M, Weems K, Saver JL. Identifying stroke in the field. Prospective validation of the Los Angeles Prehospital Stroke Screen (LAPSS). Stroke. 2000; 31:7176. [PubMed: 10625718]

4. Kothari RU, Pancioli A, Liu T, Brott T, Broderick J. Cincinnati prehospital stroke scale: reproducibility and validity. Ann Emerg Med. 1999; 33:373-378. [PubMed: 10092713]

5. Bray JE, Martin J, Cooper G, Barger B, Bernard S, Bladin C. Paramedic identification of stroke: community validation of the Melbourne ambulance stroke screen. Cerebrovasc Dis. 2005; 20:2833. [PubMed: 15942171]

6. Demaerschalk BM, Miley ML, Kiernan TE, Bobrow BJ, Corday DA, Wellik KE, Aguilar MI, Ingall TJ, Dodick DW, Brazdys K, Koch TC, Ward MP, Richemont PC. Stroke telemedicine. Mayo Clin Proc. 2009; 84:53-64. [PubMed: 19121244]

7. Pervez MA, Silva G, Masrur S, Betensky RA, Furie KL, Hidalgo R, Lima F, Rosenthal ES, Rost N, Viswanathan A, Schwamm LH. Remote supervision of I V-tPA for acute ischemic stroke by telemedicine or telephone before transfer to a regional stroke center is feasible and safe. Stroke. 2010; 41:e18-e24. [PubMed: 19910552]

8. de Villiers L, Kalula SZ, Burch VE. Does multidisciplinary stroke care improve outcome in a secondary-level hospital in South Africa? Int J Stroke. 2009; 4:89-93. [PubMed: 19383048]

\section{Appendix}

In this section, a few successful scenarios from different parts of the world and different medical systems are described to illustrate what can be done to make acute stroke treatment more widely available depending on the local conditions. 
I. The statewide program of stroke unit care and implementation of thrombolysis in the German State of Baden-Württem-berg, in which the Ministry of Health, together with stroke physicians, has embarked on a statewide program to improve stroke management, is described.

II. The strategies for improvement of prehospital management of patients with stroke in the United States is described, a process which was primarily triggered by stroke physicians.

III. The government-led nationwide system of medical emergencies, including stroke, which has been started in Brazil is reviewed.

IV. The example of South Africa is presented, which shows how stroke medicine can be brought into rural areas with the help of metropolitan stroke centers, which themselves are not similar to centers found in western Europe or North America.

V. The current attempts being undertaken in the United Kingdom in organizing stroke center care in the metropolitan areas are also reviewed.

VI. The current efforts being undertaken in the Russian Federation to improve stroke care are also described.

\section{The Stroke Unit System in Baden-Württemberg, Germany}

Approximately 10 years ago, the first stroke units were established in the State of BadenWürttemberg. Once the idea of creating stroke units in this state came up, the state government together with an action group of stroke physicians created a master plan. A program, in which 7 comprehensive stroke centers, all with intensive care units, neurosurgery, and interventional neuroradiology, were initiated. In addition, 12 regional stroke units in close cooperation with some of the comprehensive stroke centers were established. Finally, another 25 local stroke units serving rural areas, smaller cities, and remote districts were introduced, for which a close connection with either regional stroke units or stroke centers was required. The creation of this 3-level stroke unit system was very successful and the certification of the stroke units was in the hands of the stroke physicians with official recognition by the government. There is a statewide compulsory documentation for all hospitals that receive patients with stroke, although they do not have a certified stroke unit.

The yearly reports are extremely helpful and eye-opening. The incidence of strokes in the state is much higher than was initially believed. In 2008, more than 36,000 patients with stroke have been treated in hospitals of the State of Baden-Württemberg, which translates into an incidence of 360 for 100,000 residents per year. The report also shows that $>70 \%$ of all patients in the state are now being treated in certified stroke units or in intensive care units with only $30 \%$ of patient remaining in nonspecialized wards.

Interestingly the statewide use of recombinant tissue plasminogen activator is almost $6 \%$ with up to $20 \%$ in some of the comprehensive stroke centers. Intensive care unit treatment for stroke is available for approximately 12 to $15 \%$ of the patients with stroke, specifically for subarachnoid hemorrhage, intracerebral hemorrhage, and severe ischemic stroke.

Intensive care unit treatment takes place in hospitals with certified stroke service, mostly on neurologically run intensive care units. In addition to the provision of acute care, stroke unit treatment, thrombolysis, and intensive care unit care, there is also an improvement in the introduction of secondary prevention methods. 


\section{The US Preclinical Services}

In the United States, throughout the past decade, a remarkable transformation in the prehospital system of care has been underway that is expanding the access of patients with stroke to proven stroke therapies. The general framework for this evolution has been the policy and scientific statements of the AHA/ASA and the Brain Attack Coalition [1,2] that recommend the development of regional systems of stroke care in which ambulances bring patients with acute stroke directly to hospitals certified to rapidly and reliably provide approved stroke therapies. Three types of stroke-receiving facilities are recognized: (1) primary stroke centers that are able to provide organized inpatient stroke pathway care and intravenous fibrinolysis; (2) comprehensive stroke centers that provide endovascular, neurosurgical, neurointensive care, and other advanced treatments; and (3) stroke support hospitals that can provide initial interventions and then send patients to a definitive care center. These are often supported by telemedicine connections to a primary stroke center. The system is made possible by widespread adoption in the United States of training for ambulance dispatchers and paramedics in prehospital stroke recognition using validated instruments like the Los Angeles Prehospital Stroke Screen [3], the Cincinnati Prehospital Stroke Scale [4], and the Expanded Los Angeles Prehospital Stroke Screen (also known as MASS) [5] and by growing dissemination of stroke telemedicine (telestroke) systems [6, 7].

In the United States, prehospital emergency medical systems are regulated primarily at the state and county level. Hence, progress has occurred in a saltatory fashion as more state and county systems adopt the regionalized stroke care system model. Initial efforts have focused most intensively on implementing primary stroke center systems with less widespread, but still growing, use of comprehensive stroke centers and stroke support hospitals. As the first decade of the 21st century closes, at the end of 2009, 13 states and additional large counties have in place regional systems of stroke care in which patients with stroke are brought directly to > 850 primary stroke centers certified by either the Joint Commission on Hospital Accreditation or by state public health agencies. The initial adopters have tended to be larger states and counties, so that currently approximately $51 \%$ of all Americans, 154 million people, live in a jurisdiction in which, when they activate the 911 emergency response system, they will be brought to a hospital certified to be able to provide rapid and effective basic acute stroke care. Efforts continue to further expand the system to smaller and rural areas with the long-term goal of assuring all patients with acute stroke access to proven therapies.

\section{The Brazilian Program}

Brazil is a country of 190 million inhabitants with enormous social, cultural, and economic differences. The population receives public medical assistance paid by the federal government and only $20 \%$ of patients have private health insurance. Stroke is the first cause of death killing 90,000 Brazilians every year. In June 2008, the Coordination of Urgency and Emergency of the Ministry of Health started a stroke project built by the vascular neurologists. The Brazilian Stroke Network was founded to enable hospitals to treat acute stroke, train the emergency and stroke team, and organize local networks with the national prehospital medical systems (Serviço de Atendimento Móvel de Urgência [SAMU]). Four levels of stroke hospitals were defined: (1) Level A: a comprehensive stroke center; (2) Level B: a hospital with neurologist and CT scan available $24 \mathrm{~h}$ a day but without MRI or endovascular intervention; (3) Level C: a remote center for thrombolysis with telemedicine connected to a Level A center (for areas without neurologist); and (4) Level D: a hospital without structure for thrombolysis. 
All patients with stroke who receive thrombolysis are being included in the SITS Registry. In overcrowded emergencies rooms, vascular units have been defined as a geographic area with monitored beds for all kinds of acute vascular diseases such as stroke, myocardial infarction, aortic diseases, and pulmonary embolism. The vascular unit combines the benefits of acute stroke units and chest pain units and has a trained emergency team to start the protocol with the support of neurologists 24 hours a day for stroke treatment.

In each state, the program was tailored according to the local conditions (infrastructure and technical staff) and was developed together with local health authorities. Each hospital was visited, classified, and certified by stroke neurologists.

The pilot project was developed in Porto Alegre, south of Brazil. Within 1 year, 4 stroke centers were started and an increase in the number of thrombolyzed patients was seen. The program will be expanded to 15 of the 26 states.

\section{Stroke Care in South Africa}

In 2007, the South African Stroke Foundation amalgamated with the South African Heart Foundation to form the South African Heart and Stroke Foundation. The objective of this organization is to improve public awareness of cardiovascular disease through the media by providing information on all aspects of stroke (symptoms, risk factors, prevention, treatment, rehabilitation and coping strategies, etc).

Although national guidelines recommend that the stroke unit model of care be implemented in the healthcare system, it is acknowledged that in South Africa, the stroke unit model of care has not been widely implemented despite compelling evidence of efficacy, including published data from a stroke unit in a small secondary-level South African Hospital in Cape Town [8].

Many problems beset the implementation of current proposed guidelines for stroke care. Most hospitals have not developed protocols for stroke care and often there are no systems in place for patients after discharge. In certain provinces, stroke is not considered a priority by the local health authority given the burden of the HIV epidemic. Shortages and pressure for hospital beds frequently result in patients with stroke being discharged early.

Currently there is only 1 comprehensive acute stroke unit in an academic tertiary hospital in the country (Groote Schuur Hospital [GSH], University of Cape Town). A stroke training course (12 modules) was developed on-site for nurses and allied professionals and has attracted staff from other local hospitals. This unit has assisted in the establishment of stroke services and units at other hospitals in both the public and private sector.

Essential to achieving improved stroke care would be the development of a stroke training program that could be used for onsite inservice training in stroke care at all levels of the South African healthcare system in the different provinces. After discussions with the Directorate of Chronic Diseases, National Department of Health, the University of Cape Town (UCT) stroke unit has engaged in an initiative to develop such a program with the South African Department of Health. The objectives of this undertaking include: (1) develop and expand the UCT/GSH course modules on stroke care in a format for use for inservice training at healthcare facilities nationally in both the public and private sector; (2) to develop core competencies for stroke care; (3) the training program addresses principles of management that are in accordance with those in the national guidelines for stroke care; (4) program to be inclusive and representative of cultural and ethnic diversity of peoples of South Africa. Material from all provinces incorporated into the program; (5) the training program should be tailored to the resources (physical/ and staff) available at all levels of 
inpatient health care (Levels 1, 2, and 3 hospitals, with more advanced competencies required for Levels 2 and 3); (6) format of the program must be accessible and easy to use even in remote settings; (7) program to enable capacitybuilding among healthcare workers; and (8) develop criteria for accreditation of stroke training within our healthcare system.

The overall objective of developing the UCT training course in stroke care suitable for inservice training on a national level would be to facilitate the implementation of the stroke unit model of care (as detailed in the new draft national guidelines) more widely within the healthcare system.

The national Department of Health has recommended that the Western Cape Province would be ideal as a pilot site to both develop and evaluate such a program. The Western Cape Health authority has approved the development of the first module of the course for evaluation and feedback. It is envisaged that such a training program would be of value not only in South Africa, but also in other developing countries with similar resource constraints.

\section{Implementing Stroke Infrastructure in the United Kingdom}

Provision of acute stroke care is undergoing major change and improvement across the United Kingdom. Improving stroke care is a major healthcare priority in the United Kingdom, which has an underpinning English Stroke Strategy. In the United Kingdom, a major media campaign using the FAST (Facial weakness, Arm weakness, Speech problems and Time to call 999) assessment has increased public awareness. All centers receiving patients with acute stroke are now expected to be able to provide rapid admission to an acute stroke unit with multidisciplinary care and the expertise to deliver thrombolysis when indicated. This is leading to major service reconfiguration in some areas such as London where all patients with acute stroke (11,000 per annum) will be directed to 8 hyperacute stroke units. Ambulance services are now playing a key role in ensuring early accurate triage of patients to these units. Thrombolysis is now delivered to approximately $3 \%$ of UK patients with stroke and the rate is increasing rapidly. Access to imaging has improved substantially in recent years but only a few centers are currently able to offer a 24/7 interventional stroke neuroradiology service.

In England and Scotland, parallel stroke networks covering populations of approximately 2 million have been created to improve clinical care. The National Institute for Health Research Stroke Research Network provides research support through 8 local research networks in England (3 to 6 million population), which work closely with the clinical networks. Similar networks have been established in Scotland, Wales, and Northern Ireland. Over two thirds of UK stroke services are now involved in clinical research. Participation in acute stroke research correlates with improved standards of acute stroke care. National audit programs conducted annually have facilitated improvements in care across the United Kingdom.

\section{The Russian Federation Approach}

In 2006, the Public Health Ministry of the Russian Federation together with the National Stroke Association made a decision to create and introduce the 'State Government Program of Development of Stroke Care System in the Russian Federation.' This program was created in 2007 and included 3 main components: (1) developing a primary stroke prevention strategy according to the population-based risk profile; (2) creating the stroke unit system in all regions of the country (for the 142 million Russian population); and (3) developing a quality control and management system mechanism. 
The network of primary stroke units (30 beds per 200,000 adult population) and comprehensive (regional) stroke centers are to be implemented in all regions of the Russian Federation based on 2 principles: access to transportation (30 to $40 \mathrm{~min}$ from call to door, including rural and remote regions) and adequate coverage of population (1 stroke unit for 200,000 population). Each primary stroke unit is to be equipped with an express-laboratory, CT scanner, ultrasound, intensive care unit, multidisciplinary rehabilitation facilities, and operating room facilities for emergency. A program has been created, in which each region of Russia will have 1 to 3 comprehensive stroke centers ( 1 center per 1.2 to 2.0 million population). All of these will have not only basic facilities, but also vascular neurosurgery, interventional neuroradiology, and a telemedicine consultative center. Each comprehensive stroke center will be connected with a network of 3 to 6 primary stroke units with telemedicine and perform the function of coordinating activities of all attached primary stroke units, providing them with clinical and radiological support. All primary stroke units and comprehensive stroke centers work according to common National Stroke Standards and are enrolled on the common computerized 'National Stroke Registry' program with a system of quality control and quality management of stroke care (by means of tariff setting rules with adequate penalties and incentives). To train staff, special educational programs were developed (for multidisciplinary teams and all necessary specialists). More than 1,500 specialists are training on these courses annually.

The program is financed from federal budget and from budgets of constituent territories of the Russian Federation. In 2008, the program was first started in 12 regions of the Russian Federation. Data collected over the 9 months of 2009 demonstrated its high efficiency. More than $90 \%$ of all patients with stroke in these 12 regions are now being treated in stroke units (instead of 30 to $40 \%$ in the previous year). Four hundred sixty-three patients received treatment with recombinant tissue plasminogen activator during this period. The percentage of patients independent in daily living at Day 30 increased to 37\%, and 30-day mortality rate decreased to $14.6 \%$. Most significantly, stroke mortality in the whole Russian Federation decreased by $8.5 \%$ in that period compared with 2008 .

In 2009, the program was implemented in 12 more regions of the Russian Federation. In 2010, it will start in another 14 regions and by 2013, the new system of stroke care will be deployed in all 83 regions of the country. 


\section{World internet penetration rates by geographic regions}

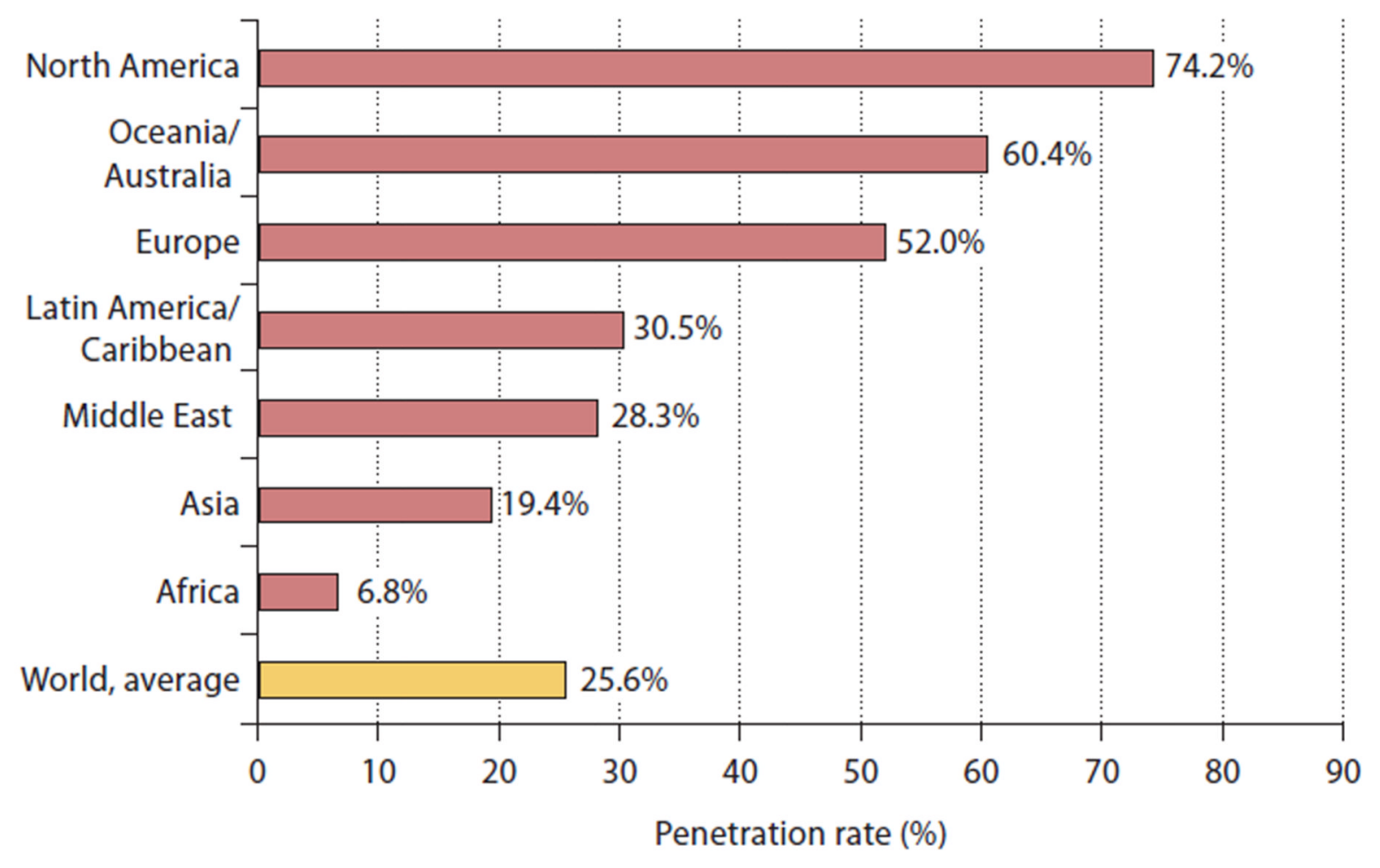

Fig. 1.

Source: Internet world stats. Available at: www.internetworldstats.com/ stats.htm. Penetration rates are based on a world population of 6,767,805,208 and 1,733,993,741 estimated Internet users for September 30, 2009. Copyright 2009, Miniwatts Marketing Group. 